\title{
Numerical Study of Reasonable Cycle Step Length for Longwall Top-coal Drawing in Extra-thick Coal Seams Based on the Particle-block Element Coupling Approach
}

\section{Yaochuang Wang}

Henan Polytechnic University

Dongyin Li

Henan Polytechnic University

Shen Wang ( $D$ wangshen2019@126.com )

School of Energy Science and Engineering, Henan Polytechnic University, Jiaozuo, 454003, China

Shiting Zhu

Tongxin coal mine, Datong coal mine group

\section{Zuguang Wang}

Henan Polytechnic University

\section{Research}

Keywords: longwall top-coal drawing, reasonable cycle step length, extra-thick coal seams, particle-block element coupling approach, top-coal recovery rate

Posted Date: November 2nd, 2020

DOI: https://doi.org/10.21203/rs.3.rs-99111/v1

License: (c) (i) This work is licensed under a Creative Commons Attribution 4.0 International License.

Read Full License 


\section{Numerical study of reasonable cycle step length for longwall top-coal drawing in extra-thick coal seams based on the particle-block element coupling approach}

Yaochuang Wang ${ }^{1}$, Dongyin $\mathrm{Li}^{1}$, Shen Wang ${ }^{1,2, *}$, Shiting Zhu ${ }^{3}$, Zuguang Wang ${ }^{1}$

${ }^{1}$ School of Energy Science and Engineering, Henan Polytechnic University, Jiaozuo, 454003, China

${ }^{2}$ Postdoctoral Station of Safety Science and Engineering, Henan Polytechnic University, Jiaozuo, 454003, China

${ }^{3}$ Tongxin Coal Mine, Datong Coal Mine Group Co., Ltd. Datong, 037003, China

* Correspondence should be addressed to: Shen Wang, wangshen@hpu.edu.cn

E-mail addresses:

yaochuang_w@163.com (Yaochuang Wang)

lidongyin@126.com (Dongyin Li)

wangshen@hpu.edu.cn (Shen Wang)

18234249436@163.com (Shiting Zhu)

111702010004@home.hpu.edu.cn (Zuguang Wang) 
Abstract: The cycle step length (CSL) is a significant parameter for longwall top-coal drawing technology that remarkably affects the top-coal recovery rate and the rockmixing rate, especially for extra-thick coal seams. In this study, a particle-block element coupling approach is performed to investigate a reasonable CSL for extra-thick coal seams. By comparing this approach to the Bergmark-Roos analytical result, the proposed numerical model is verified, showing good performance in modeling top-coal caving. A 2-D numerical model of hydraulic support considering the mechanical behavior of the legs is established, which can be used for modeling the interaction between the hydraulic support and the top coals during the top-coal drawing process. The top-coal recovery rate, the top-coal drawing body shape, and the evolution characteristics of the coal-rock interface under different CSL conditions are compared. In addition, the mechanism of the lost top coal affected by the CSL is revealed. The results show that the CSL of top-coal drawing has a significant effect on the morphology of the coal-rock interface and the mutual invasion of coal and rock, which is the primary reason for coal loss and further affects the top-coal recovery rate and the rock-mixing rate. It is suggested that the CSL should be $0.8 \mathrm{~m}$ when the top-coal thickness is $12 \mathrm{~m}$.

Keywords: longwall top-coal drawing; reasonable cycle step length; extra-thick coal seams; particle-block element coupling approach; top-coal recovery rate

\section{Introduction}

Coal resources will still play a pivotal role in the proportion of energy consumption in the future. In China, thick coal seams (thickness $\geq 3.5 \mathrm{~m}$ ) account for approximately $45 \%$ of the total coal reserves. There are three mining techniques used for thick coal seams: longwall fully mechanized mining with a large cutting height, longwall fully mechanized top-coal caving (LTCC), and slicing mining. As early as the early 20th century, LTCC was first applied in the Blanche coal mine in France, but it was only used for special mining in steep coal seams, corner coal, coal pillars, and other complex geological environments. Thereafter, the former Soviet Union, Romania, Spain, the former Yugoslavia, Hungary, and other countries gradually began to formally study the 
applicability of LTCC in thick coal seams. In China, LTCC began in the 1980s but developed rapidly. At present, LTCC has gradually become the most popular method for mining thick or extra-thick coal seams (Xie and Zhao 2009; Wang et al. 2014; Yang et al. 2016), and China is in the leading position in the world in studying automated LTCC technology(Yasitli and Unver 2005; Ediz et al. 2006; Wang 2018). In traditional top-coal mining technology, the drawing process is observed by workers through a gap between hydraulic supports. "Rocks appear at the coal drawing opening" is commonly regarded as the criterion for terminating the coal drawing. However, because of the hysteresis of the closing action response under manual operation, the top coal will still flow out with many rocks before the openings are closed, resulting in a high rockmixing rate. With the introduction of automation and artificial intelligence technology into the mining industry, more than 100 longwall working faces have been equipped with automated and intelligent coal cutting technologies (e.g., automatic alignment technology of the working face and distinguishing technology of coal and rock)(Ma 2013; Wang et al. 2018a, 2018b, 2018c). However, the high rock-mixing rate and low top-coal recovery rate (most are lower than 65\% in extra-thick coal seams) are still outstanding problems for LTCC. It is widely thought that the CSL is significantly related to the above two rates (Vakili and Hebblewhite 2010), but the influence mechanism of the CSL remains unclear.

The theoretical study of LTCC in China lags behind its engineering application. In the early stage, the top-coal caving and flow laws are attracted. The ellipsoid theory of metal ore caving was first introduced into the study of top-coal drawing to explore the shape of the top-coal drawing body and put forward the ellipsoid theory for coal drawing (Wu 1991; Yan and Wu 1996; Wu and Zhang 1998). Since 2000, low-level caving hydraulic support has been widely used in China. Through simulation tests, numerical analysis, and field observations, the theory of granular medium flow for topcoal drawing was proposed, which considered the influences of the CSL, shield beam, and tail beam on hydraulic support, and then, the boundary-body-ratio (BBR) research system was established to study the four factors of the coal-rock interface, top-coal drawing body, top-coal recovery rate, and rock-mixing rate (Wang and Fu 2002; Wang 
et al. 2004, 2015, 2016a). Numerical simulation has also developed rapidly into an effective method for studying LTCC. Khanal et al. $(2011,2014)$ established a numerical LTCC model with COSFLOW software and analyzed the support collapse, top coal failure mechanism, roof caving mechanism, support stress, and vertical stress on the caving effect and finally discussed the feasibility of using LTCC technology in the Adriyala coal mine. Simsir F et al. (2008) simulated the coal production of an LTCC working face using ARENA software and found that the one-per-two reamer method has a higher top-coal recovery rate. In addition, the finite difference method was used to analyze the mechanism of top-coal caving in the Omerler coal mine (Yasitli and Unver 2005; Unver and Yasitli 2006). Using PFC2D, Xie and Zhao (2009) proved that the top-coal arch structure can be caused only by gravity conditions and is easily damaged by vibration. Wang et al. (2013) performed PFC3D to study the influence of hydraulic support on the shape of the top-coal drawing body and believed that the topcoal drawing body was a variant ellipsoid cut by the shield beam of hydraulic support. Liu et al. (2019) used CDEM software to study the coal drawing methods and evolution characteristics of the coal-rock interface at the different stages of initial coal caving, intermediate coal caving, and end coal caving under the condition of multiple top-coal drawing openings. Zhang et al. (2019) studied the law of fully mechanized top-coal caving mining in extra-thick coal seams based on the continuous medium discontinuous element method.

Because of the complex environment behind hydraulic supports, it is difficult to observe the top-coal caving process above the hydraulic support. A numerical simulation is thus a fast and effective way to simulate the top-coal caving process. The particle element method is the major simulation method used for studying top-coal drawing, but modeling the interaction between the hydraulic support and the top coal during the drawing process presents a challenge. In this study, the particle-block element coupling approach is used to simulate the longwall top-coal drawing process. The block mesh model and the constitutive law of hydraulic support are proposed, and the interaction principle between particles and block elements is introduced. The process of top-coal drawing with a single coal drawing opening is modeled and verified 
with the Bergmark-Roos analytical model. Then, the correlation between the top-coal recovery rate and the shape of the coal-rock interface is analyzed, and based on this result, a reasonable CSL for extra-thick coal seams is determined.

\section{Governing equations}

\subsection{The interaction principle between particle and block element}

In a numerical simulation method of top-coal mining, the flow of particles from aggregates broken into loose and falling particles can well simulate the top-coal drawing process and the coal-rock interface state. In addition, a hydraulic support numerical model is added to the simulation process. The block element can accurately simulate and analyze the stress state of the coal rock and hydraulic support so that the simulation result of the top-coal drawing process is closer to the actual situation of the project. The calculation principle of particle and block coupling used in this paper is as follows (Potyondy and Cundall 2004; Feng et al. 2015; Zhang et al. 2020a; Zhang et al. 2020b).

The internal mechanical calculation of the block element adopts the explicit solution method to calculate the finite element, including the calculation of the element node force and the calculation of the element node motion.

The calculation formula of the resultant force on the element node is as follows:

$$
F=F_{e}+F_{d}+F_{c}
$$

where $F$ is the resultant force of the element node, $F_{e}$ is the external force of the element node, $F_{D}$ is the deformation force of the element node, and $F_{C}$ is the damping force of the element node.

The calculation formula of node movement is as follows:

$$
\begin{gathered}
a=F / m \\
v=\sum_{t=0}^{\text {Tnow }} a \cdot \Delta t \\
\Delta u=v \cdot \Delta t \\
u=\sum_{t=0}^{\text {Tnow }} \Delta u
\end{gathered}
$$

where $a$ is the acceleration of the node of the calculation element; $v$ is the velocity of the node of the calculation element; $\Delta u$ is the displacement increment of the node of the calculation element; $u$ is the full amount of the node displacement of the 
calculation element; $m$ is the mass of the node of the calculation element; and $\Delta t$ is the node of the calculation element time step.

Using the incremental calculation method to calculate the stress of the element and the node deformation of the element gives the following:

$$
\begin{gathered}
\{\Delta \xi\}_{i}=[B]_{i} \cdot\{\Delta u\}_{e} \\
\{\Delta \sigma\}_{i}=[D]_{i} \cdot\{\Delta \xi\}_{i} \\
\{\Delta \sigma\}_{i}=\left\{\sigma^{0}\right\}_{i}+\{\Delta \sigma\}_{i} \\
\left\{F_{n}\right\}_{e}=\sum_{i=1}^{N}[B]_{i}^{T} \cdot\left\{\sigma^{n}\right\}_{i} \cdot \omega_{i} \cdot J_{i}
\end{gathered}
$$

where $[B]_{i},\{\Delta \xi\}_{i},\{\Delta \sigma\}_{i}, \omega_{i}$, and $J_{i}$ are the strain calculation matrix of Gaussian point $i$, the vector of incremental strain, the vector of incremental stress, the integral coefficient and the Jacobian determinant; $\left\{\Delta \sigma^{n}\right\}_{i}$ and $\left\{\sigma^{0}\right\}_{i}$ are the total stress at the current time and the previous time of Gaussian point $i$ for the calculation element; $[D],\{\Delta u\}_{e}$, and $\left\{F_{d}\right\}_{e}$ are the elastic matrix of the calculation element, the displacement vector of the incremental node of the calculation element and the vector of the node force of the calculation element; $N$ is the number of Gaussian points.

The linked bar model can be used to simulate the continuous medium properties between the particles. A connecting rod model is established between the two particle elements, as shown in Figure 1. It is used to simulate the process from the initial intact state to crushing of the top-coal drawing. The link bar model is regarded as a rectangle, through which the contact force or cohesive force between the two particle elements can be calculated. The long side of the rectangle is the sum of the radii of the two particles, while the short side is equal to the diameter of the smaller particles. Based on the connecting rod model, the relationship between the two particle elements is the surface contact, and the equivalent contact area $A_{C}$ is the projected area of the smaller particles. 


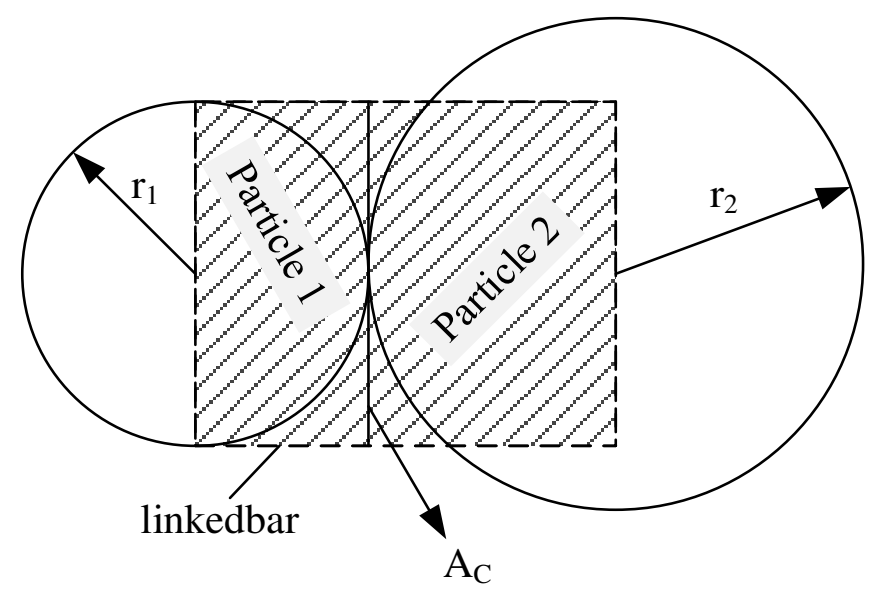

Figure 1 The linked bar model

The formula for calculating the contact force between the discrete elements of the particles is as follows:

$$
\begin{aligned}
& F_{n}(t+\Delta t)=F_{n}(t)-K_{n} \Delta u_{n} \\
& F_{s}(t+\Delta t)=F_{s}(t)-K_{s} \Delta u_{s}
\end{aligned}
$$

where $\Delta u_{n}$ and $\Delta u_{s}$ are the incremental difference of the normal displacement and the incremental difference of the tangential displacement between two discrete elements of particles in contact with each other.

The formula for calculating the contact torque between discrete elements of particles is as follows:

$$
\begin{aligned}
& M_{n}(t+\Delta t)=M_{n}(t)-K_{s} J \Delta \theta / A_{c} \\
& M_{s}(t+\Delta t)=M_{s}(t)-K_{n} I \Delta \theta_{s} / A_{c}
\end{aligned}
$$

where $M_{n}$ and $M_{s}$ are the torque and bending moment between the discrete elements of the particles, $I$ and $J$ are the moment of inertia and the moment of inertia between the contact surfaces of the discrete elements of the particles, and $\Delta \theta$ and $\Delta \theta_{s}$ are the incremental differences between the torsion and bending angles between the discrete elements of the particles.

$$
\begin{gathered}
J=\pi\left(R_{1}+R_{2}\right)^{4} / 32 \\
I=J / 2 \\
A_{c}=\min \left(2 R_{1}, 2 R_{2}\right)
\end{gathered}
$$

where $R_{1}$ and $R_{2}$ are the radius values of the two particles contacting each other between the discrete elements of the particles, and $A_{c}$ is the contact area between the discrete elements of the particles. The contact stiffness between the discrete elements of the particles can be derived from the elastic modulus and shear modulus of the 
particles in contact with each other:

$$
\begin{aligned}
K_{n} & =\bar{E} A_{c} /\left(R_{1}+R_{2}\right) \\
K_{s} & =\bar{G} A_{c} /\left(R_{1}+R_{2}\right)
\end{aligned}
$$

where $K_{n}$ and $K_{s}$ are the normal and tangential stiffness $\bar{E}$ between the discrete elements of the particles in contact with each other, and $\bar{G}$ is the average elastic modulus and the shear modulus of the two discrete elements of the particles in contact with each other.

According to the Mohr-Coulomb criterion and the maximum tensile stress criterion, the contact force calculation formula is as follows:

$$
\begin{gathered}
\text { If }-F_{n}-T A_{c} \geq 0, \text { then } F_{n}=F_{s}=0, T=C=0 \\
\text { If } F_{s}-F_{n} \tan \varphi-C A_{c} \geq 0, \text { then } F_{n}=F_{s} \tan \varphi=0, T=C=0
\end{gathered}
$$

The contact judgment condition between the two particle elements is formula (1.9). If any one of the inequalities in the formula is satisfied, the contact between the particles will no longer transmit torque.

$$
\begin{aligned}
& \left(\frac{-F_{n}}{A_{c}}+\frac{M_{s}}{I} R_{\text {ave }}\right)-T \geq 0 ; \text { or } \\
& \left(\frac{\left|F_{s}\right|}{A_{c}}+\frac{M_{s}}{I} R_{\text {ave }}\right)-\left[F_{n} \tan \varphi+C\right] \geq 0
\end{aligned}
$$

where $R_{\text {ave }}=\left(R_{1}+R_{2}\right) / 2, T, C$, and $\varphi$ are the tensile strength, cohesion and internal friction angle, respectively, and $I$ is the moment of inertia.

The calculation of the torque on the particle discrete element is as follows:

$$
\Delta d=\left(\omega_{1} \omega_{1}-\omega_{2} \omega_{2}\right) \Delta t+\left(v_{1}-v_{2}\right) \Delta t
$$

where $\omega_{1}$ and $\omega_{2}$ are the vectors of the rotational angular velocity of particle discrete elements 1 and $2 ; r_{1}$ and $r_{2}$ are the vectors of the relative positions of particle discrete elements 1 and 2 to the contact point (from the particle centroid to the contact point); and $v_{1}$ and $v_{2}$ are the translational velocity vectors of the centroid of particle discrete elements 1 and 2 .

$$
M_{1}=r_{1} F^{(G)} ; M_{2}=-r_{2} F^{(G)}
$$

where $M_{1}$ and $M_{2}$ are the torque on particle discrete elements 1 and 2, respectively, and $F^{(G)}$ is the contact force of the particle discrete element in the global coordinate system. 
The core of the coupling calculation of the block element and the particle discrete element is the logical judgment of the mutual contact between the block element and the particle discrete element. In the two-dimensional numerical calculation, the method for judging the contact between the block element and the particle discrete element is the body center of the particle element. To judge the relative position of contact with the edge of the block element, the contact between the body center of the particle element and the edge of the block element must also satisfy that the distance from the body center of the particle discrete element to the boundary edge of the block element is less than or equal to the radius of the particle discrete element. That is $d \leq R$, and the projection point of the body center of the discrete element of the particle on the boundary edge of the block element is inside the edge of the block element, that is, $d_{i k} \leq d_{i j}, d_{j k} \leq d_{i j}$ can be established. Once the particle discrete element and the edge of a boundary block element have established a contact relationship, the normal spring and tangential spring that contact each other between the block element and the particle discrete element are automatically created, and the block element contacts the particle discrete element. The interpolation coefficient of point $k$ will be automatically calculated by the following formula:

$$
\begin{gathered}
d=\left|V_{k i} \cdot n\right| \\
\omega_{i}=d_{j k} / d_{i j} \\
\omega_{j}=d_{i k} / d_{i j}
\end{gathered}
$$

where $V_{k i}$ is the relative position vector of the particle from the element center $k$ and the block element edge $i, i$ and $j$ are the two endpoints of the block edge, $d_{j k}$ is the distance between point $j$ and point $k, d_{i j}$ is the difference between point $i$ and point $j$, dik is the distance between point $i$ and point $k$, and $n$ is the normal vector outside at the edge of the block.

According to the alternating cycle calculation process of the theoretical formula (1 12), the explicit solution process for the finite element, discrete element, particle, and block coupling can be realized.

\subsection{The constitutive law of hydraulic support}

In previous simulation methods for top-coal drawing, most scholars used PFC to 
simulate the top-coal drawing process. To more realistically simulate the top-coal drawing process at the top-coal drawing working face, the constitutive model of the top-coal hydraulic support is put into the CDEM simulation. According to the coupling principle of block and particle introduced in Section 2.1, the interaction between the coal gangue particles and the hydraulic support for the top-coal drawing and the change process of the working resistance of the hydraulic support during the top-coal drawing process are simulated to more truly simulate the on-site coal caving process. The test points are arranged between the inner and outer columns of the hydraulic support, as shown in Figure 2(a). The red point is the measuring point of the working resistance of the hydraulic support for top-coal drawing. The hydraulic support model adopts the constitutive model, which can represent the relationship between the column shrinkage and the working resistance. The calculation formula is as follows:

$$
P_{1}=P_{0}+K \Delta S
$$

where $P$ is the working resistance of the support; $P_{0}$ is the setting force of the support; $K$ is the hydraulic stiffness; $\Delta S$ is the shrinkage of the column.

The numerical constitutive curve of the hydraulic support is shown in Figure 2(b) (Liu et al. 2018). Figure 2(b) shows that the constitutive structure of the stent in the simulation has two stages. In the first stage, the support resistance from the initial support force $P_{0}$ to the working resistance $P_{1}$ with stiffness $K$ linearly increases as the column shrinks down. The safety valve opens in the second stage, and the working resistance of the support will not change as the column continues to shrink. As the working face advances, the hydraulic support is recycled from the above process.

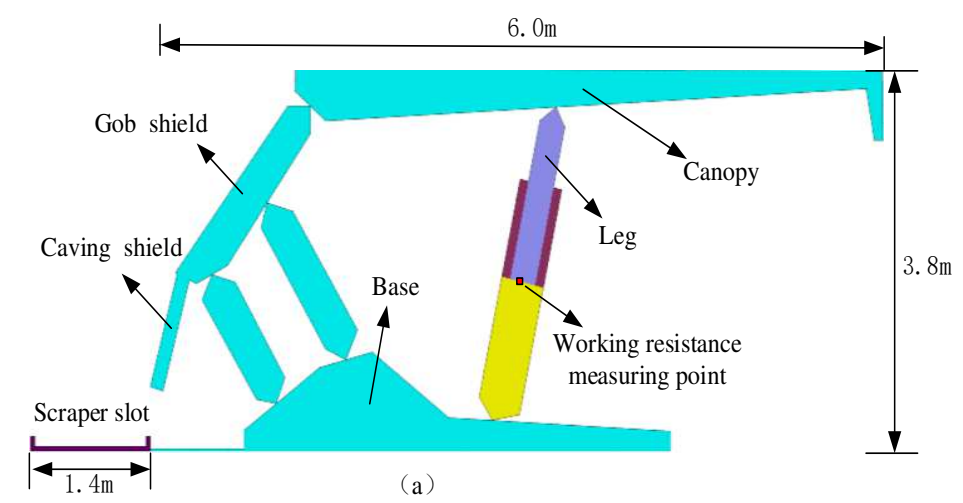




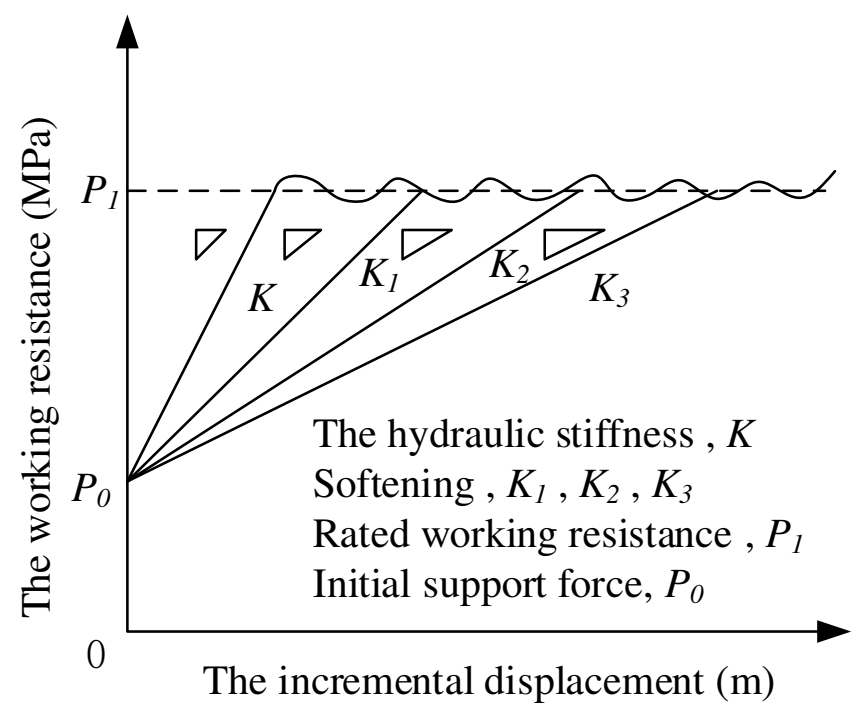

(b)

Figure 2 (a) Numerical model and arrangement of measuring points and (b) numerical constitutive curve of support

\section{Validation for the proposed particle approach}

\subsection{The Bergmark-Roos model}

Here, we adopt the Bergmark-Roos analytical model to benchmark the proposed particle approach. The top coal is disturbed by mining and is broken into blocks under the combined action of the overlying rock layer and the hydraulic support. It is discharged through the drawing opening at the rear of the hydraulic support. However, the coal mining process on the cross-section parallel to the working face is not affected by the structure of the hydraulic support. Therefore, the top-coal drawing theory of a single drawing opening parallel to the cross-section of the working face can be interpreted by the Bergmark-Roos theory (KUCHTA 2002; Melo et al. 2007; Wang et al. 2016).

The Bergmark-Roos model mainly assumes that the broken top coal moves from a static straight line to the top-coal drawing opening. During the top-coal drawing process, the broken top coal is only affected by gravity and friction. During the top-coal drawing process, the acceleration of a single crushing top coal block is constant. The architecture of the Bergmark-Roos model is shown in Figure 3 (a). 


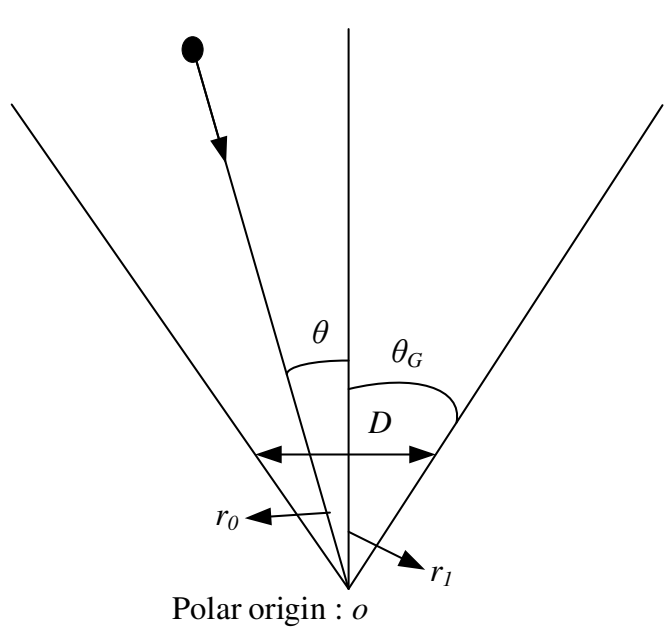

(a) Architecture of the Bergmark-Roos model

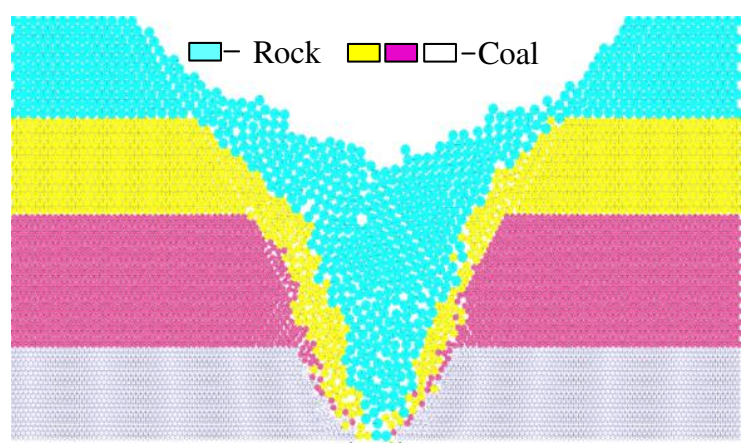

(c) The coal-rock interface after coal drawing

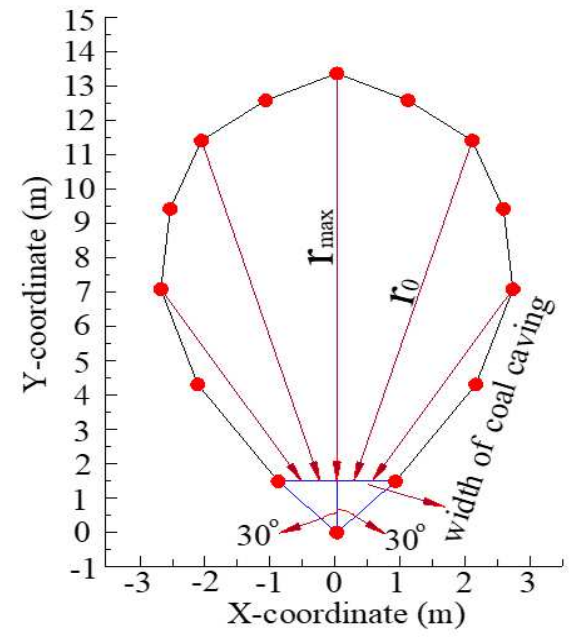

(b) theory model

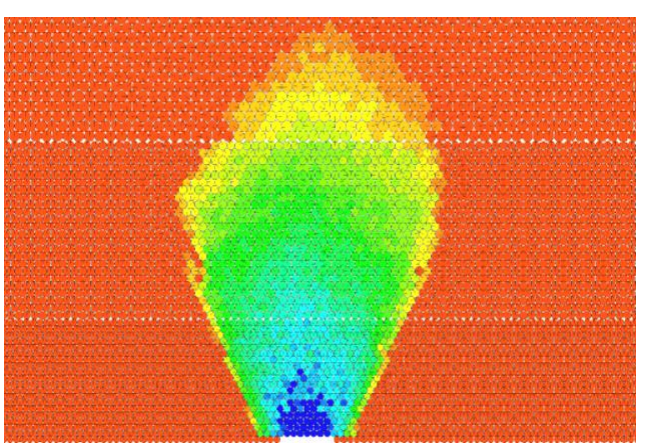

(d) Top coal caving body diagram

Figure 3 Comparison between the theoretical model and the numerical results of the top-coal drawing body

The boundary equation of the top-coal drawn in the polar coordinate system is as follows:

$$
r_{0}=\left(r_{\text {max }}-r_{1}\right) \frac{\cos \theta-\cos \theta_{G}}{1-\cos \theta_{G}}+r_{2}
$$

According to Figure 3(a), the distance from the origin of the coordinates to any point on the opening on the drawing is as follows:

$$
r_{2}=\frac{r_{1}}{\cos \theta}=\frac{D}{2 \tan \theta_{G} \cos \theta}
$$

where

$$
r_{1}=\frac{D}{2 \tan \theta_{G}}
$$

Putting equations (15) and (16) into (14), we obtain:

$$
r_{0}=\left(r_{\text {max }}-\frac{D}{2 \tan \theta_{G}}\right) \frac{\cos \theta-\cos \theta_{G}}{1-\cos \theta_{G}}+\frac{D}{2 \tan \theta_{G} \cos \theta}
$$


where $r_{l}$ is the distance from the center of the drawing opening to the origin of the polar coordinates; $r_{2}$ is the distance from any point on the drawing opening to the origin of the polar coordinates; $\theta$ is the angular coordinate of the particle; $\theta_{G}$ is the maximum allowable displacement boundary angle. The force is equal to the angle of the particle weight; when $\theta=0, r_{\max }$ is the maximum distance from the origin of polar coordinates to the boundary of the drawing body; and $D$ is the size of the opening in the figure.

\subsection{Comparison}

According to the real dimension of the drawing opening, a 1.75 m wide opening is set at the bottom of the model to simulate the coal drawing opening. The top coals are fully broken before being drawn out. Therefore, the top coal strength parameter is set to 0 in this simulation. The termination condition for the end of coal drawing is "rocks appear, close the opening". As shown in Figure 3 (c), the coal-rock interface is funnel-shaped after top-coal drawing at a single coal drawing opening. To study the shape, trajectory and initial position of the loose body discharged through the coal drawing port, the numerical simulation adopts the method of reverse marking the position of the drawing body in the original mold at a specific time after recovering the loose body. In Figure 3 (d), particles with the same color in the model are obtained by the reverse marking of a loose body released within a period, and the shape of top-coal released resembles an approximate ellipsoid state.

According to the ellipsoid theoretical simulation equation of formulas (16) and (17), the single coal drawing port model shows that the thickness of the top coal is $r_{1}=12 \mathrm{~m}$, and the size of the coal drawing opening is $d=1.75 \mathrm{~m}$. From the numerical simulation of a single coal drawing opening, $\theta_{G}=30^{\circ}$ can be obtained, and equation (17) is simplified to equation (18):

$$
r_{0}=\frac{12(2 \cos \theta-\sqrt{3})}{2-\sqrt{3}}+\frac{7 \sqrt{3}}{8 \cos \theta}
$$

According to formula (18), the theoretical model of the shape of the top-coal drawing body parallel to the cross-section of the working face is shown in Figure 3(a). As shown in Figure 3 (c), the top coal in the ellipsoid range can be finally discharged 
through the coal drawing port. Some of the top-coal particles outside the ellipsoid boundary are loose and not drawn out.

\section{Numerical model}

\subsection{Determination of numerical model parameters}

The coal seam thickness of the no. 8222 fully mechanized top-coal caving panel in the Tashan coal mine is $8.17-29.21 \mathrm{~m}$, with an average of $15.76 \mathrm{~m}$; it has a mining height of $3.8 \mathrm{~m}$ and a utilization thickness of 7.81-22.11 m, with an average of $15.6 \mathrm{~m}$, and a direct roof thickness of 1.51-14.52 m, with an average of $8.22 \mathrm{~m}$. According to a geological report, the fractures of the coal seams are well-developed, and it exhibits a fragmentary uneven ladder-shaped fracture and has developed endogenous fractures. The coal is loose in structure, brittle and fragile, the joint spacing is $15 \sim 25 \mathrm{~cm}$, and therefore the top coal is easily drawn out. To ensure the cutting depth and effective moving distance, the ZF17000/27.5/42D top-coal drawing hydraulic support was adopted. The stroke of the pushing jack of the support is $1120 \mathrm{~mm}$. The height of the support is $2.75-4.2 \mathrm{~m}$. The yield resistance of the hydraulic support is $17000 \mathrm{kN}$ and its off-loading strength of the safety valve is $41.8 \mathrm{MPa}$. The working parameters of the support is shown in Table 1 below. To create the hydraulic support model, the simplified initial support diagram is first established with a height of $3.8 \mathrm{~m}$ in AutoCAD software, as shown in Figure 2(a). According to the actual size of the hydraulic support in Figure 2(a) and the specific position of the rear scraper conveyor, the coupling mesh model of the hydraulic support is created by ANSYS and CDEM software, as shown in Figure 4. A $6 \mathrm{~m}$ rock gangue layer above the top coal is established to simulate crushing of the immediate roof. Along the strike of the working face, the length of the numerical model is $118 \mathrm{~m}$. To eliminate the influence of the rigid boundary on the top-coal drawing body, a boundary width of $25 \mathrm{~m}$ is set on the left and right sides, respectively. The particle mechanical parameters, particle size, and layer height parameters used in the numerical simulation are shown in Table 2 and Figure 4.

Table 1 The parameter values of the ZF17000/27.5/42D top-coal drawing hydraulic support 


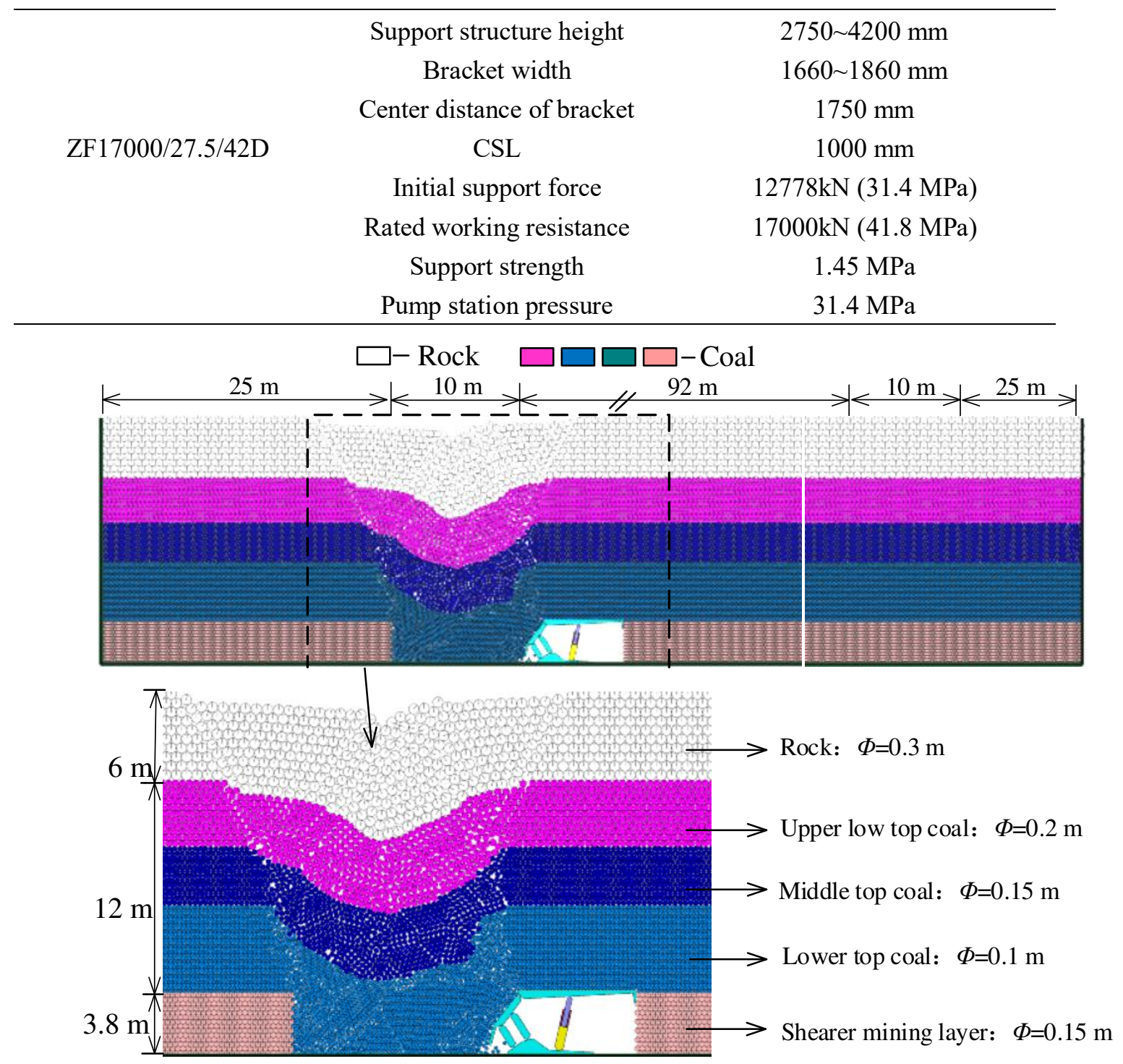

Figure 4 Numerical model

Table 2 Values of the coal particle mechanical parameters adopted in this study

\begin{tabular}{cccccccc}
\hline Stratum & $\begin{array}{c}\text { Density } \\
\left(\mathrm{kg} / \mathrm{m}^{3}\right)\end{array}$ & $\begin{array}{c}\text { Elastic } \\
\text { modulus } \\
(\mathrm{Pa})\end{array}$ & $\begin{array}{c}\text { Poisson's } \\
\text { ratio }\end{array}$ & $\begin{array}{c}\text { Tensile } \\
\text { strength } \\
(\mathrm{Pa})\end{array}$ & $\begin{array}{c}\text { Cohesion } \\
(\mathrm{Pa})\end{array}$ & $\begin{array}{c}\text { Internal } \\
\text { friction } \\
\left({ }^{\circ}\right)\end{array}$ & $\begin{array}{c}\text { Local } \\
\text { damping } \\
\text { coefficient }\end{array}$ \\
\hline $\begin{array}{c}\text { Coal seam } \\
\text { Gangue layer in } \\
\text { coal seams }\end{array}$ & 1373 & $2.8 \times 10^{9}$ & 0.3 & 0 & 0 & 44.8 & 0.05 \\
Immediate roof & 1800 & $4.2 \times 10^{9}$ & 0.25 & 0 & 0 & 35.8 & 0.05 \\
\hline
\end{tabular}

\subsection{Numerical simulation scheme}

To study the influence of different CSLs on top-coal recovery and the evolution of the coal-rock interface, the numerical simulation uses "rocks appear, close the opening" as the termination criteria of top-coal drawing. In this study, to investigate the influence of the CSL on the top-coal recovery rate and the evolution of the coal-rock interface, 
the CSL is set from $0.6 \mathrm{~m}$ to $1.6 \mathrm{~m}$ with an interval of $0.1 \mathrm{~m}$. The advancing direction is from left to right, and the initial top-coal drawing is carried out after the advance of $10 \mathrm{~m}$ from the open cut. After the numerical simulation calculation is terminated, the top coal yield within a single moving frame cycling under different CSLs is counted, the final top-coal recovery rate is calculated, and the top-coal recovery rate is compared with the top-coal recovery rate under different CSLs to determine the optimal caving step distance.

The numerical model uses particle flow to simulate the fully mechanized caving mining process along the direction of the working face. To simplify and facilitate the numerical simulation calculation, basic assumptions are made on the drawing top-coal strata (Wu and Chen 1999; Huang et al. 2016):

a. The top coal is loose and broken and does not bear tensile stress;

b. The top coal is regarded as a quasi-rigid body;

c. The hydraulic support only bears the weight of the broken top coal and rock layer above;

d. In the top-coal drawing process, there is no wall spalling or roof falling at the end face.

\section{Numerical results and discussion}

\subsection{Evolution analysis of the coal gangue interface}

Figure 5 shows the development of the top-coal drawing body in the initial drawing. In the initial stage of top-coal drawing, the top coal is fully drawn out, and the ellipsoid of top-coal drawing is affected by the tail beam and shield beam of the hydraulic support, showing the shape of a cutting variant ellipsoid. For the first coal drawing at the end, the coal drawing funnel is fully developed, and the influence of the top-coal drawing hydraulic support deflects to one side of the gob. 


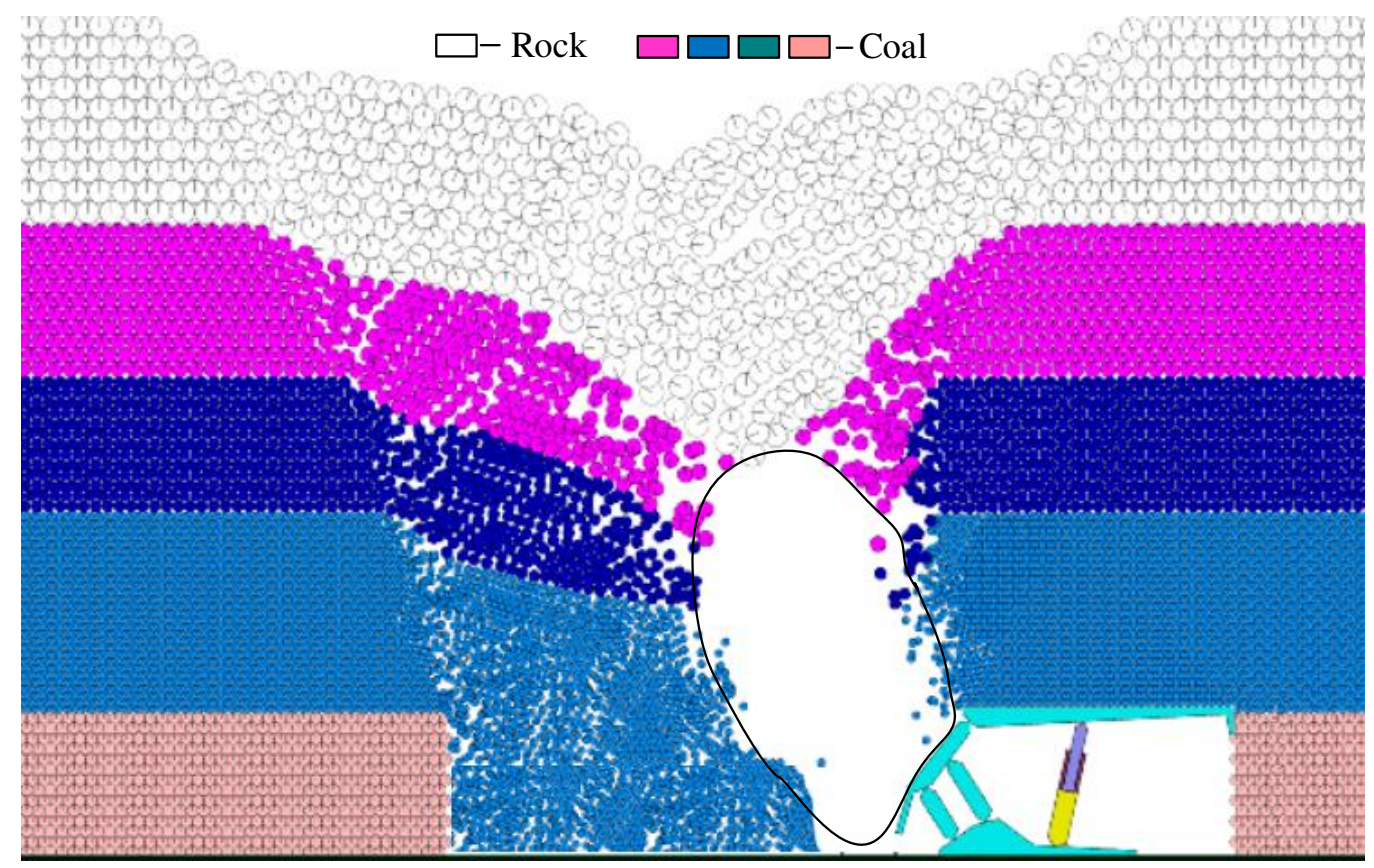

Figure 5 The top-coal caving body shape

Taking $0.8 \mathrm{~m}$ and $1.4 \mathrm{~m}$ top-coal drawings as an example, in Figure 6 below, the evolution of the coal-rock boundary under the condition of different drawing CSLs during the top-coal drawing process can be clearly compared. The coal-rock boundary is fully developed to the rear of the gob, and is affected by the hydraulic support and becomes steeper on the side of the coal wall, showing a hook-like shape. When CSL is $1.4 \mathrm{~m}$, the back hook of the coal-rock boundary on one side of the coal wall to the gob side is more obvious than that under CLS $=0.8 \mathrm{~m}$. It is revealed that CSL has an effect on the deflection angle of the development of the coal drawing ellipsoid and the coalrock interface; as the working face continues to move forward, the top coal above the hydraulic support will reach the coal drawing opening earlier than the top coal behind the hydraulic support, resulting in strip coal loss.

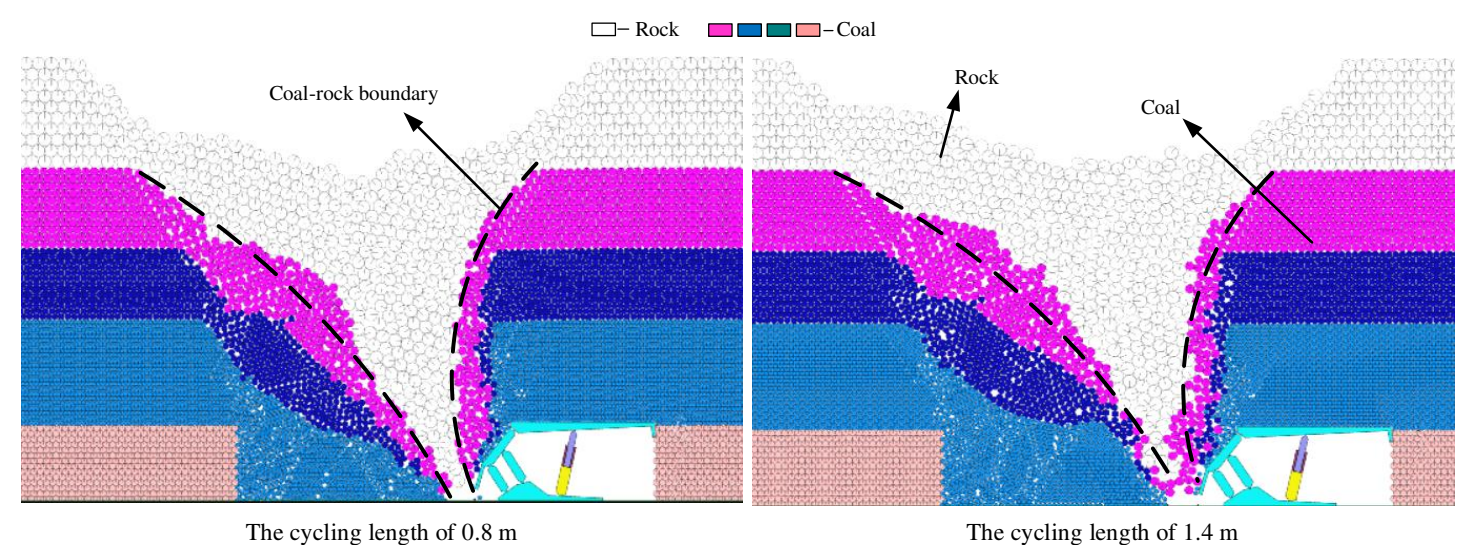

(a) The first coal caving 


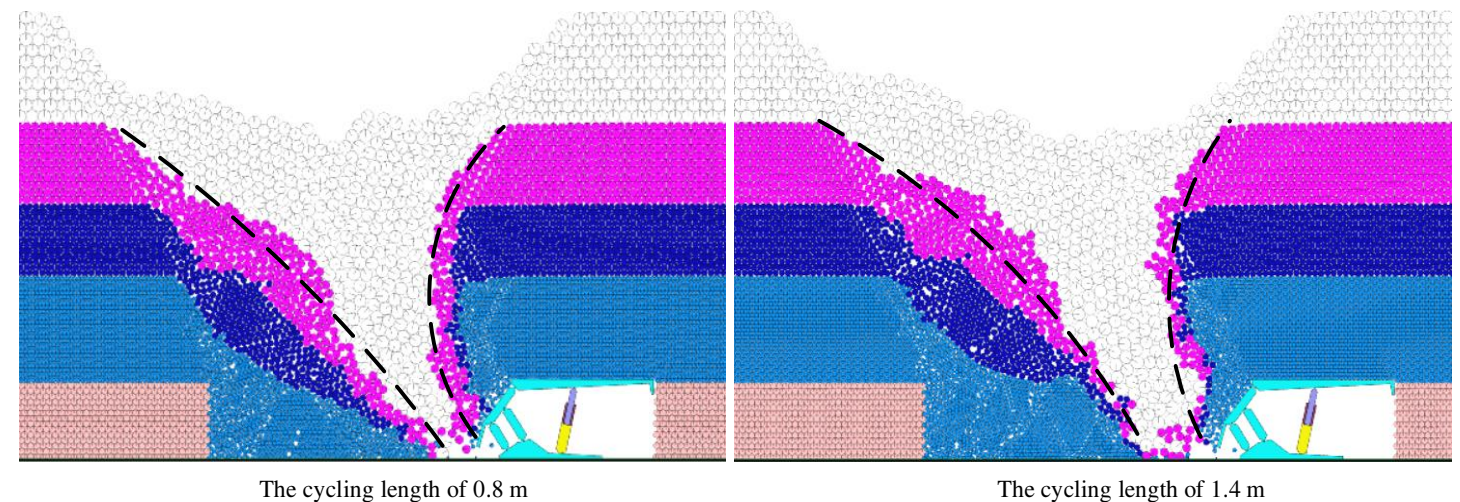

(b) The third coal caving

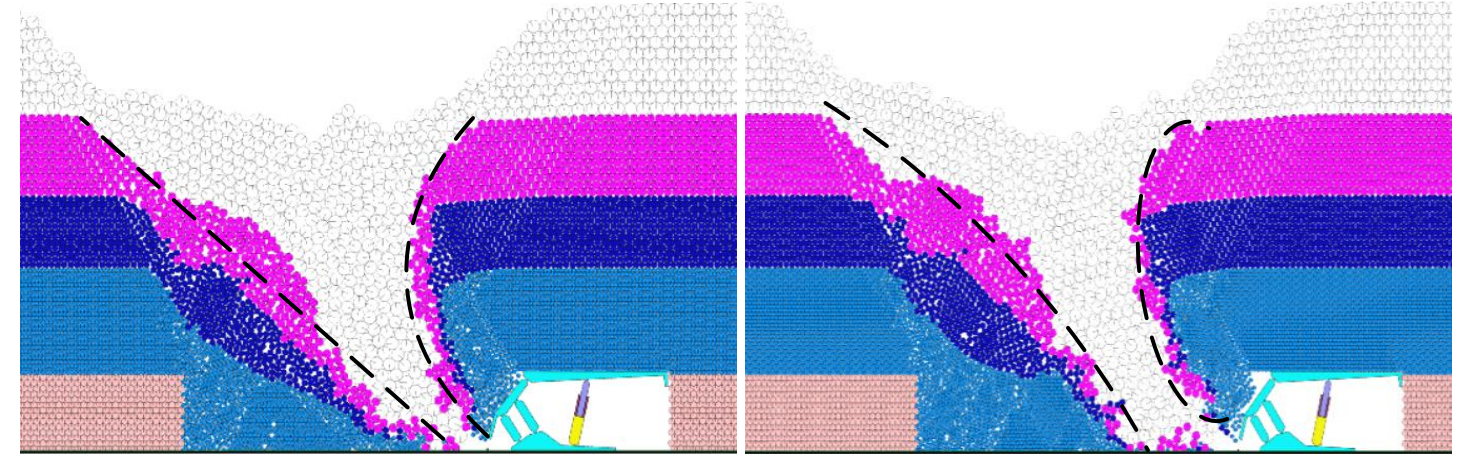

The cycling length of $0.8 \mathrm{~m}$

(c) The fifth coal caving

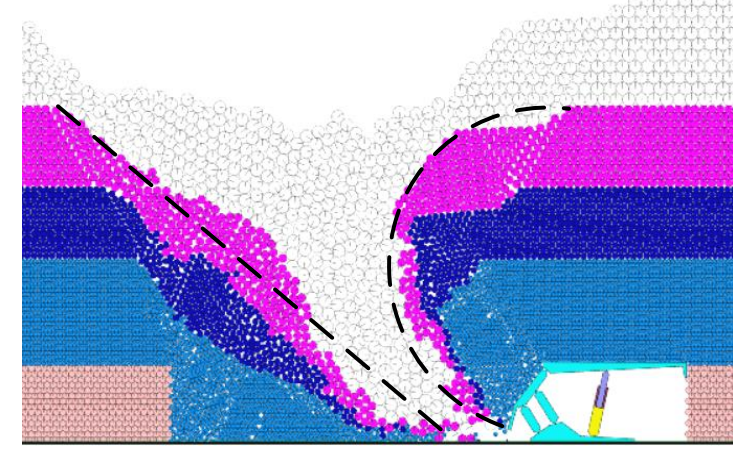

The cycling length of $0.8 \mathrm{~m}$

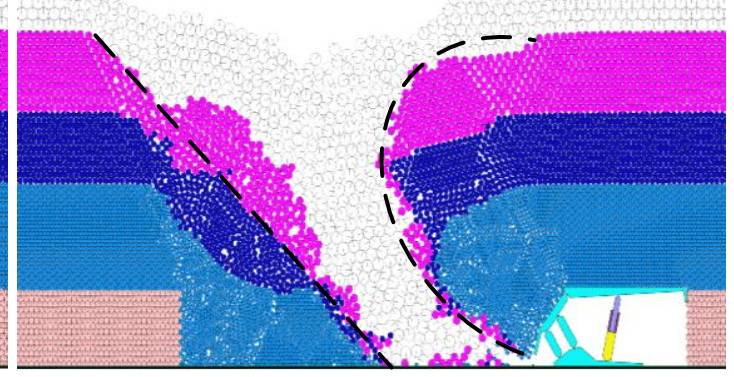

The cycling length of $1.4 \mathrm{~m}$

(d) The 7th coal caving

Figure 6 Evolution of the rock-coal interface during the first 7 top-coal drawing cycles

The mechanism of the lost coal in the gob with a strip distribution (as shown in Figure 7) are discussed as follows. When the coal drawing hydraulic support starts to advance, the funnel shape formed by the interface between the coal drawing ellipsoid and the coal-rock interface is affected by the coal drawing hydraulic support, and only a small amount of top coal above the hydraulic support flows to the coal drawing opening. With the continuous advance of the working face, the top coal on the side of the coal wall begins to be released, resulting in the rock above the hydraulic support reaching the coal drawing opening in advance, so a part of the top coal on the side of the gob will be left in the gob. The boundary of coal and rock on the side of the coal 
wall develops laterally to the side of gob again and becomes tortuous and irregular from the loose extrusion of top coal in the longitudinal direction, which forms a cycle of "upper top coal preferentially discharging - upper rock arriving at the coal drawing opening before the rear top coal - top coal remaining - upper top coal developing towards the gob", resulting in part of the top-coal circulation remaining in the gob. In Figure 7 below, it can be clearly seen that a strip-shaped lost coal is left in the gob. Therefore, in can be inferred that CSL has a significant effect on the amount of the lost coal.

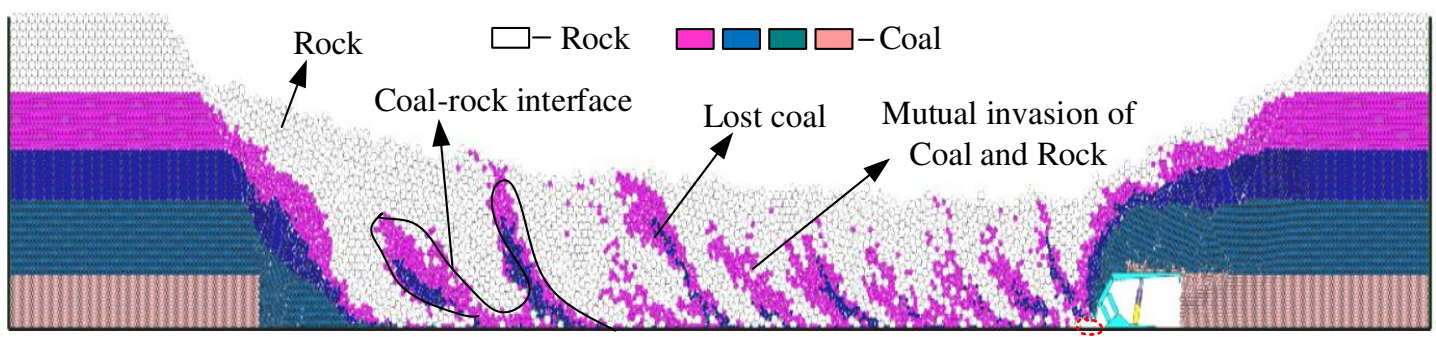

Figure 7 Drawn top-coal caving situation under the cycle step length of $0.8 \mathrm{~m}$

\subsection{Determination of the best coal caving step}

The drawn amount of top-coal drawing in each drawing cycle under different CSL conditions is shown in Figure 8 below. It can be seen that, regardless of the adopted coal drawing CSL, the first drawn amount is the largest, and the drawn amount increases with the increase of coal drawing CSL. Figure 9(a) shows the average value and standard deviation of the top-coal yield in each advancing cycle, from which the dispersion degree of the top-coal yield in different CSLs is significantly different. Under the condition of CSL $=0.8 \mathrm{~m}$, the top-coal yield is the highest. From Figure 9(b), it can be seen that with the continuous advance of the working face, the top-coal drawing amount increases steadily. When $\mathrm{CSL}=0.8 \mathrm{~m}$, the increase in drawn top-coal amount is the most linear, and the final yield is the largest. The larger the difference in top-coal yield between the adjacent coal drawing cycles is, the greater the fluctuation of coal-rock decomposition surface evolution. Therefore, under the condition of CSL $=$ $0.8 \mathrm{~m}$, the coal-rock interface is the gentlest, and the coal loss is the least. 


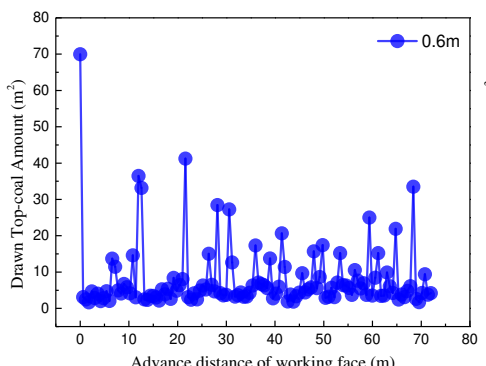

(a)

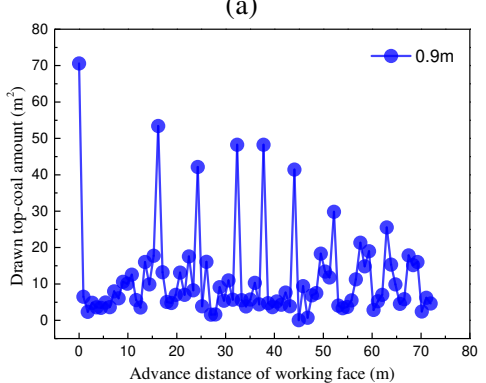

(d)

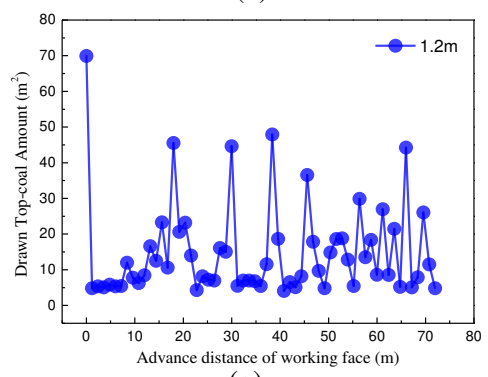

(g)

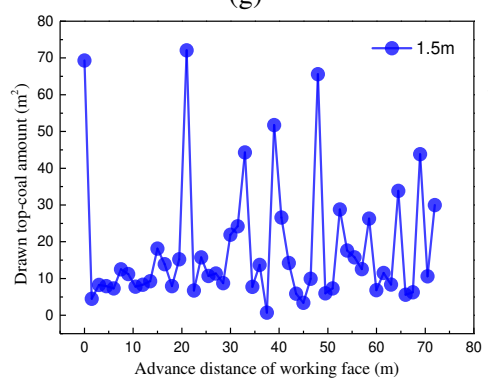

(j)

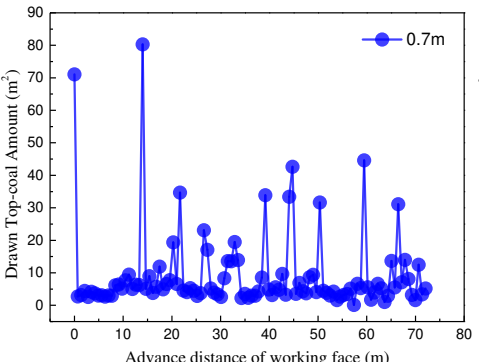

(b)

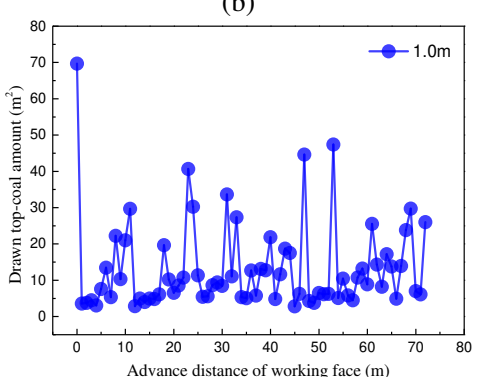

(e)

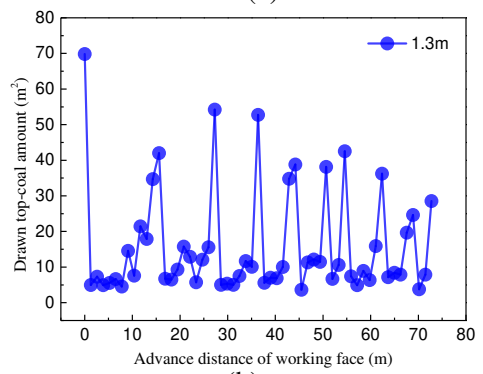

(h)

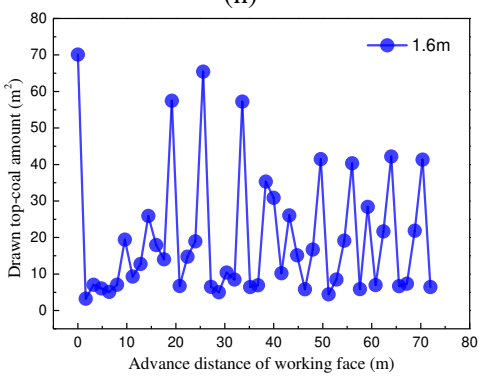

(k)

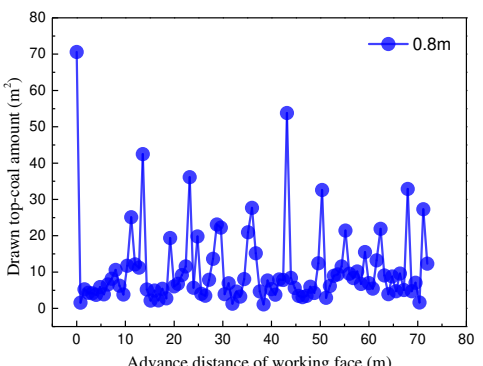

(c)

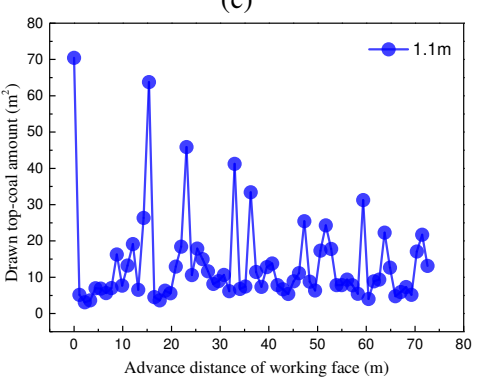

(f)

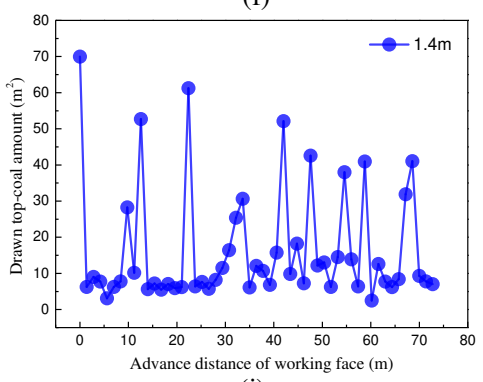

(i)

Figure 8 The amount of top-coal drawing at a single CSL under different drawing CSLs

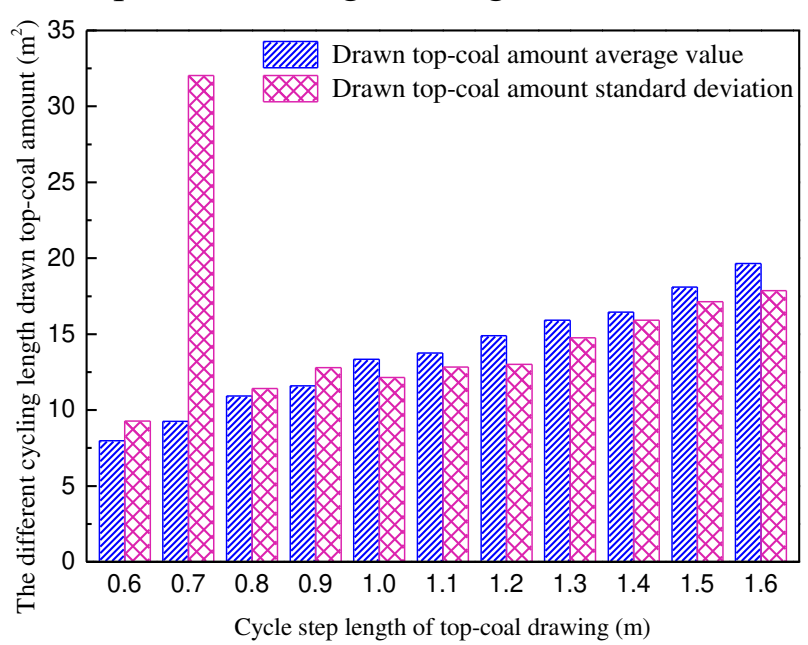

(a) 


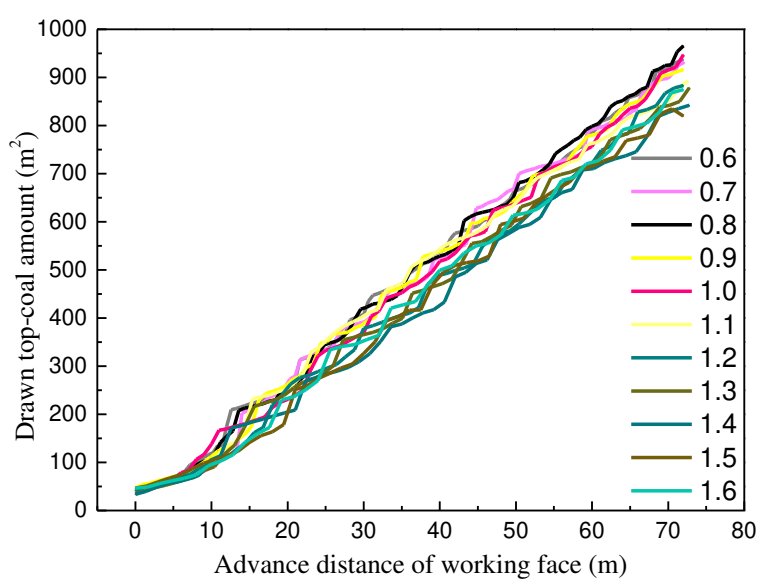

(b)

Figure 9 (a) Comparison of the average value and standard deviation of top-coal discharge within a single moving step of different coal drawing CSLs, and (b) Variation diagram of top-coal discharge with increasing advancing distance

Using the method of numerical simulation analysis, it can be seen that different results for different coal drawing CSLs can be obtained solely by analyzing the initial position of the working face and advancing to the stop position. Various types of methods are used to advance the mining and adjust the different drawing CSLs, and the total moving distance is basically the same, at approximately $92 \mathrm{~m}$. Under the $12.0 \mathrm{~m}$ top-coal thickness and different coal drawing CSL conditions, the particle area of the top-coal drawing area before the start of coal drawing requires a total of approximately $1000 \mathrm{~m}^{2}$ of top-coal storage capacity. The total area of the model particles is 2185.378 $\mathrm{m}^{2}$; the total area of the particles at the end of coal drawing, the area difference between the particles at the two ends before the beginning of the coal drawing and the end of the coal drawing, and the area of the top-coal particles is calculated. The top-coal at 12.0 $\mathrm{m}$ is the calculated thickness under the conditions of different drawing CSLs, the ratio of the area of the particles discharged from the top-coal drawing area to the area of the top-coal drawing area, and the size of the top-coal recovery rate, as shown in Table 3. The top-coal recovery rates from 11 different drawing CSLs are compared and shown in Figure 10 below.

Table 3 Statistical Table of Top-coal Recovery Rate

\begin{tabular}{ccccccc}
\hline Coal & Total area of & Total surface & Total area of & Area of more & Area of the & Top-coal \\
drawing & initial state & area of sphere & sphere at the & release at & sphere released & recovery \\
$\mathrm{CSL} / \mathrm{m}$ & body $/ \mathrm{m}^{2}$ & of top-coal & end of coal & both ends $/ \mathrm{m}^{2}$ & in the coal & rate $/ \%$ \\
\hline
\end{tabular}




\begin{tabular}{ccccccc}
\hline & & drawing area $/ \mathrm{m}^{2}$ & drawing $/ \mathrm{m}^{2}$ & \multicolumn{3}{c}{ drawing area $/ \mathrm{m}^{2}$} \\
\hline 0.6 & 2185.378 & 995.2016 & 1220.642 & 86.1033 & 878.6327 & 88.2869 \\
0.7 & 2185.378 & 9956414 & 1222.15 & 106.555 & 856.673 & 86.0423 \\
0.8 & 2185.378 & 995.2016 & 1190.381 & 107.364 & 887.633 & 89.1913 \\
0.9 & 2185.378 & 995.2016 & 1245.532 & 64.4498 & 875.3962 & 87.9617 \\
1.0 & 2185.378 & 995.2016 & 1211.414 & 100.8845 & 873.0795 & 87.7289 \\
1.1 & 2185.378 & 1001.689 & 1263.258 & 58.8028 & 863.3172 & 86.1862 \\
1.2 & 2185.378 & 995.2016 & 1276.9 & 64.9761 & 843.5019 & 84.7569 \\
1.3 & 2185.378 & 1003.817 & 1277.568 & 75.3826 & 832.4274 & 82.9262 \\
1.4 & 2185.378 & 1003.817 & 1313.657 & 70.6152 & 801.1058 & 79.806 \\
1.5 & 2185.378 & 995.2016 & 1298.837 & 66.7118 & 819.8292 & 82.3782 \\
1.6 & 2185.378 & 995.2016 & 1281.44 & 65.2274 & 838.7106 & 84.2754 \\
\hline
\end{tabular}

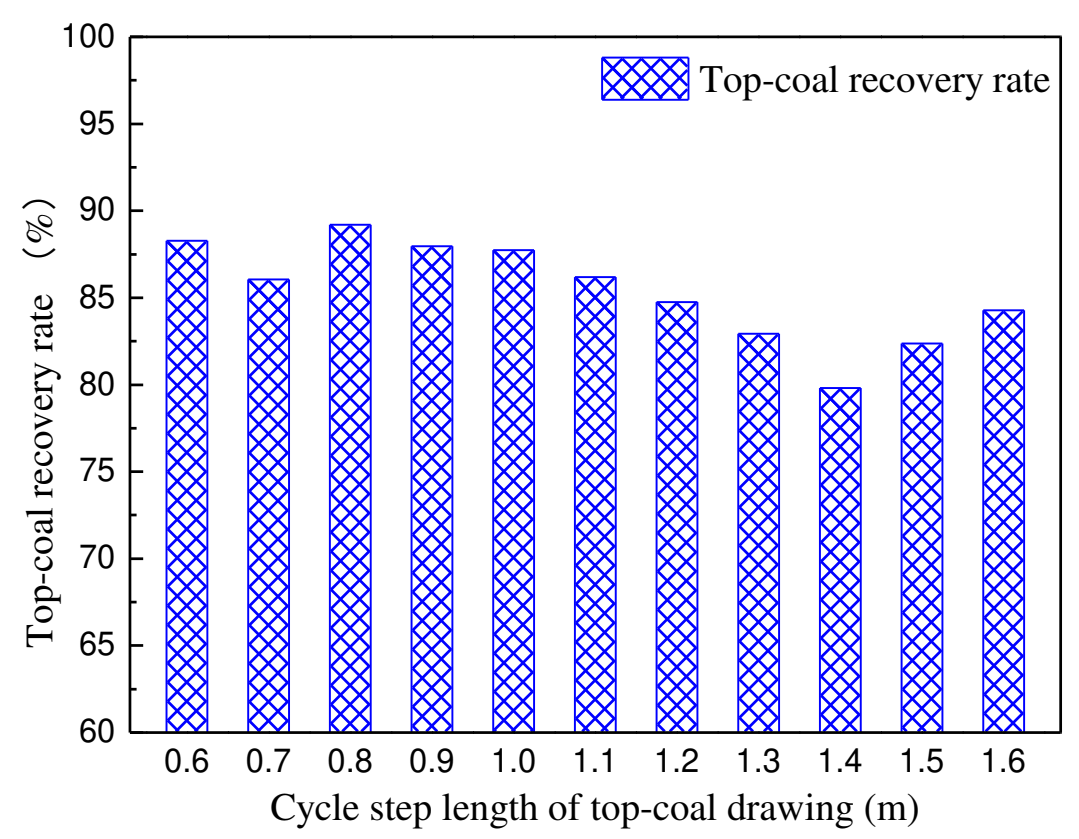

Figure 10 Change in the top-coal recovery rate under different cycle step lengths

Figure 10 shows that the top-coal recovery rate of $12.0 \mathrm{~m}$ top coal varies under different caving step conditions. Therefore, under the condition of $12.0 \mathrm{~m}$ top-coal thickness, the top-coal recovery rate can reach $89.12 \%$ when CSL is $0.8 \mathrm{~m}$. Therefore, it is finally determined that the most reasonable CSL is $0.8 \mathrm{~m}$ for $12 \mathrm{~m}$ top-coal thickness of the 8222 fully mechanized caving face in the Tashan coal mine.

\section{Conclusion}

In this study, a particle-block element coupling approach is implemented to investigate a reasonable cycle step length of top-coal drawing for extra-thick coal seams. The block mesh model and the constitutive law of hydraulic support are proposed, and the interaction principle between particles and block elements is introduced. The 
correlation between the top-coal recovery rate and the shape of the coal-rock interface is analyzed, and based on this result, a reasonable CSL for extra-thick coal seams is determined. The main conclusions are as follows:

(1) By comparing the numerical simulation result to the Bergmark-Roos analytical result, the proposed numerical model is verified and shows good performance in modeling top-coal caving. A2-D numerical model of hydraulic support considering the mechanical behavior of the legs is established, which can be used for modeling the interactions between hydraulic support and top coals during the top-coal drawing process.

(2) The distribution of the lost coal in gob and its mechanism are clarified. During the advance process of top-coal drawing, with the rock reaching the coal drawing opening and with periodic floating, the top-coal drawing body is affected by the tail beam of the hydraulic support, which takes the shape of a cutting variation ellipsoid. In addition, the displacement angle of the ellipsoid to one side of the gob is different with different CSLs. If the CSL is too long, the upper rock will arrive at the coal drawing opening before the coal behind the hydraulic support. If the coal drawing CSL is too short, the rock in the gob will rush into the coal drawing opening in advance. As a result, the loss of top coal is periodically inclined to one side of the gob. In each drawing cycle, the top coal flows regularly twice. The first flow is a large range of top-coal falling after the support movement, and the other flow is the process of top coal upper rock flowing with the top coal at the coal drawing opening.

(3) Combined with the actual geological situation of the no. 8222 working face, the top-coal recovery rate, the shape of the top-coal drawing body, and the evolution characteristics of the coal-rock interface under different CSL conditions are compared. In addition, the mechanism of the lost top coal affected by the CSL is revealed. The results show that the CSL of top-coal drawing has a significant effect on the morphology of the coal-rock interface and the mutual invasion of coal and rock, which is also the primary reason for coal loss and further affects the top-coal recovery rate and the rock-mixing rate. It is suggested that the CSL should be 0.8 
$\mathrm{m}$ when the top-coal thickness is $12 \mathrm{~m}$.

\section{Declarations}

We declare that we do not have any commercial or associative interest representing a conflict of interest in connection with the paper submitted.

\section{Acknowledgement}

This study was supported by the National Key R\&D Program of China (2018YFC0604502) and China Postdoctoral Science Foundation (2020M672227).

\section{References}

1. Wang JC, Yang SL, Li Y, et al. Caving mechanisms of loose top coal in longwall top coal caving mining method. Int J Rock Mech Min Sci. 2014;71:160 - 170 https://doi.org/10.1016/j.ijrmms.2014.04.024.

2. Yang SL, Zhang JW, Chen Y, et al. Effect of upward angle on the drawing mechanism in longwall top coal caving mining. Int J Rock Mech Min Sci. 2016;85:92 - 101 https://doi.org/10.1016/j.ijrmms.2016.03.004.

3. Xie YS, Zhao YS. Numerical simulation of the top coal caving process using the discrete element method. Int J Rock Mech Min Sci. 2009;46:983 - 991 https://doi.org/10.1016/j.jirmms.2009.03.005.

4. Yasitli NE, Unver B. 3D numerical modeling of longwall mining with top coal caving.Int J Rock Mech Min Sci. 2005;42:219 - 235 https://doi.org/10.1016/j.ijrmms.2004.08.007.

5. Ediz IG, Dixon-Hardy DW, Akcakoca H, et al. Application of retreating and caving longwall (top coal caving) method for coal production at GLE Turkey. Min Technol.2013;115:41 - 48 https://doi.org/10.1179/174328606X103586.

6. Wang JC. Engineering practice and theoretical progress of top coal caving mining technology in China. J China Coal Soc. 2018;43:43 - 51 https://doi.org/10.13225/j.cnki.jccs.2017.4101.

7. Wang GF, Pang YH, Ma Y, et al. Automated mining technology and equipment for fully-mechanized caving mining with large mining height in extra-thick coal seam. Coal Eng. 2018;50:1 - 6 https://doi.org/10.11799/ce201801001.

8. Ma Y. Study on automatic top coal caving system in fully-mechanized coal caving face. Coal Sci Technol. 2013;41:22 - 24 https://doi.org/10.13199/j.cnki.cst.2013.11.019.

9. Wang GF, Pang YH, Ren HW, et al. Coal safe and efficient mining theory, technology and equipment innovation practice. J China Coal Soc. 2018;43:903 - 913 https://doi.org/10.13225/j.cnki.jccs.2017.1705.

10. Wang GF, Wang H, Ren HW, et al. 2025 scenarios and development path of intelligent coal mine. J China Coal Soc. 2018;43: 5 - 305 https://doi.org/10.13225/j.cnki.jccs.2018.0152.

11. Vakili A, Hebblewhite BK. A new cavability assessment criterion for Longwall Top Coal Caving. Int J Rock Mech Min Sci. 2010;47:1317 - 1329 https://doi.org/10.1016/j.ijrmms.2010.08.010.

12. Wu J, Zhang Y. Study on the basic theory of longwall top coal caving system. J China Univ Min Technol. 1998;27:331 - 335 http://www.cnki.com.cn/Article/CJFDTotal-ZGKD804.000.htm.

13. Yan SH, Wu J. Analysis of top coal movement and damage characteristics in top coal caving. J China Coal Soc. 1996;15:155 - 162 http://www.cnki.com.cn/Article/CJFDTotal-YSLX602.010.htm.

14. Wu J. Theory and practice of sub-level caving method in China. J China Coal Soc.1991;3:1 - 11 https://doi.org/10.13225/j.cnki.jccs.1991.03.001.

15. Wang JC, FU Q. The loose medium flow field theory and its application on the longwall top coal caving. J China Coal Soc. 2002;27:337 - 341 https://doi.org/10.3321/j.issn:0253-9993.2002.04.001.

16. Wang JC, Li ZG, Chen YJ, et al. The experimental study of loose medium flow field on the longwall top 
coal caving. J China Coal Soc. 2004;29:260 - 263 https://doi.org/10.13225/j.cnki.jccs.2004.03.002.

17. Wang JC, Zhang JW, li ZL. A new research system for caving mechanism analysis and its application to sublevel top coal caving mining. Int J Rock Mech Min Sci.2016;88:273 - 285 https://doi.org/10.1016/j.ijrmms.2016.07.032.

18. Wang JC, Song ZY, Zhang JW, et al. Three-dimensional experimental study of loose top coal drawing law for longwall top coal caving mining technology. J Rock Mech and Geo Eng. 2015;7:318 - 326 https://doi.org/10.1016/j.jrmge.2015.03.010.

19 Khanal M, Adhikary D, Balusu R. Evaluation of mine scale longwall top coal caving parameters using continuum analysis[J]. Mining Science and Technology (China), 2011, 21(6): 787-796. https://doi.org/10.1016/j.mstc.2011.06.027

20 Khanal M, Adhikary D, Balusu R. Prefeasibility study-geotechnical studies for introducing longwall top coal caving in Indian mines[J]. Journal of Mining Science, 2014, 50(4): 719-732.

https://doi.org/10.1134/S1062739114040139

21 Unver B, Yasitli N E. Modelling of strata movement with a special reference to caving mechanism in thick seam coal mining[J]. International Journal of Coal Geology, 2006, 66(4): 227-252.

https://doi.org/10.1016/j.coal.2005.05.008

22 Wang JC, Wei LK, Zhang JW, et al. 3-D numerical simulation on the top coal movement law under caving mining technique. J China Coal Soc.2013;38:1905 - 1911 https://doi.org/10.13225/j.cnki.jccs.2013.11.013.

23 Vakili A, Hebblewhite BK. A new cavability assessment criterion for Longwall Top Coal Caving. Int J Rock Mech Min Sci. 2010;47:1317-1329 https://doi.org/10.1016/j.ijrmms.2010.08.010.

24 Liu Chuang, Li Huamin, Zhou Ying, Li Dongyin. Cooperative caving method with multiple caving openings in fully mechanized caving face[J].Journal of China Coal Society,2019,44(09):2632-2640.

10.13225/j.cnki.jccs.2018.1278

25 Qunlei Zhang, Jinchao Yue, Chuang Liu, Chun Feng, Huamin Li,Study of automated top-coal caving in extra-thick coal seams using the continuum-discontinuum element method,International Journal of Rock Mechanics and Mining Sciences, Volume 122,2019,ISSN 1365-1609. https://doi.org/10.1016/j.ijrmms.2019.04.019.

26 Feng C, Li SH, Liu XY. A procedure for transiting FEM into DEM and its application.Rock Soil Mech. 2015;36(4):1027 - 1034 https://doi.org/10.16285/j.rsm.2015.04.017.

27. Potyondy DO, Cundall PA. A bonded-particle model for rock. Int J Rock Mech Min Sci.2004;41:1329 1364. https://doi.org/10.1016/j.ijrmms.2004.09.011.

28 ZHANG Q L, ZHI Z H, FENG C, et al. Investigation of concrete pavement cracking under multi-head impact loading via the continuum-discontinuum element method [J]. International Journal of Impact Engineering, 2020. https://doi.org/10.1016/j.ijimpeng.2019.103410

29 ZHANG Q, YUAN R, WANG S, et al. Optimizing Simulation and Analysis of Automated Top-Coal Drawing Technique in Extra-Thick Coal Seams [J]. Energies, 2020. https://doi.org/10.3390/en13010232

30 Liu Chuang, Li Huamin, Zhang Qunlei. Research on reasonable ratio of setting force to rated working resistance of large mining height hydraulic support[J]. Journal of Mining \& Safety Engineering, 2018, 035(004):725-733. https://doi:10.13545/j.cnki.jmse.2018.04.009.

31 Wang JC, Song ZY, Zhang JW, et al. Theoretical model of drawing body in LTCC mining. J China Coal Soc. 2016;41:352-358 https://doi.org/10.13225/j.cnki.jccs.2015.1750.

32. Kuchta ME. A revised form of the Bergmark-Roos equation for describing the gravity flow of broken rock. Miner Resour Eng. 2002;11:349-360 https://doi.org/10.1142/S0950609802001002.

33. Melo F, Vivanco F, Fuentes C, et al. On drawing body shapes: from Bergmark-Roos to kinematic models. Int J Rock Mech Min Sci. 2007;44:77-86 https://doi.org/10.1016/j.ijrmms.2006.04.010. 
34 Wu Jian, Chen Xuehua. Discrete element simulation study of loose top coal falling law in fully mechanized caving mining [J]. Journal of Liaoning Technical University (Natural Sc-ience Edition), 1999, 18(6): 570-573. https://kns.cnki.net/kcms/detail/detail.aspx?FileName=FXKY199906003\&DbName=CJFQ1999

35 Huang Bingxiang, Liu Changyou, Wu Fengfeng, et al. Study on the granular model test of coal caving technology under the roof of extremely loose fine sandstone[J]. Journal of China University of Mining and Technology, 2006, 35(3): 351-355.

https://kns.cnki.net/kcms/detail/detail.aspx?FileName=ZGKD200603012\&DbName=CJFQ2006 
Figures

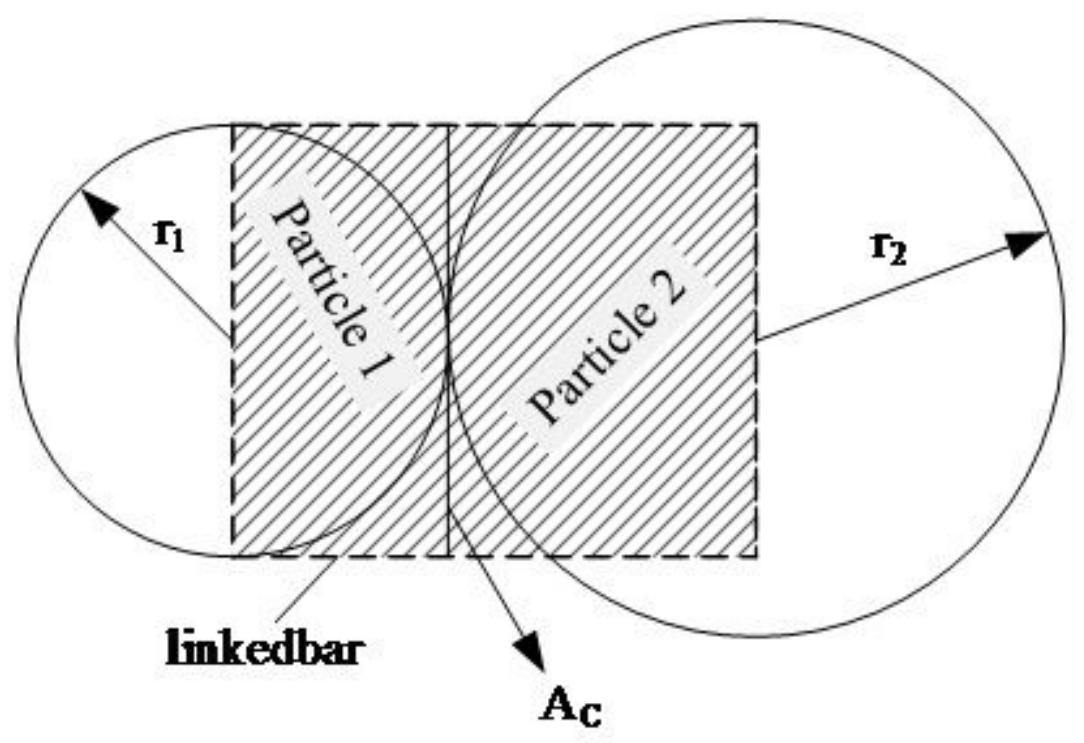

Figure 1

The linked bar model 

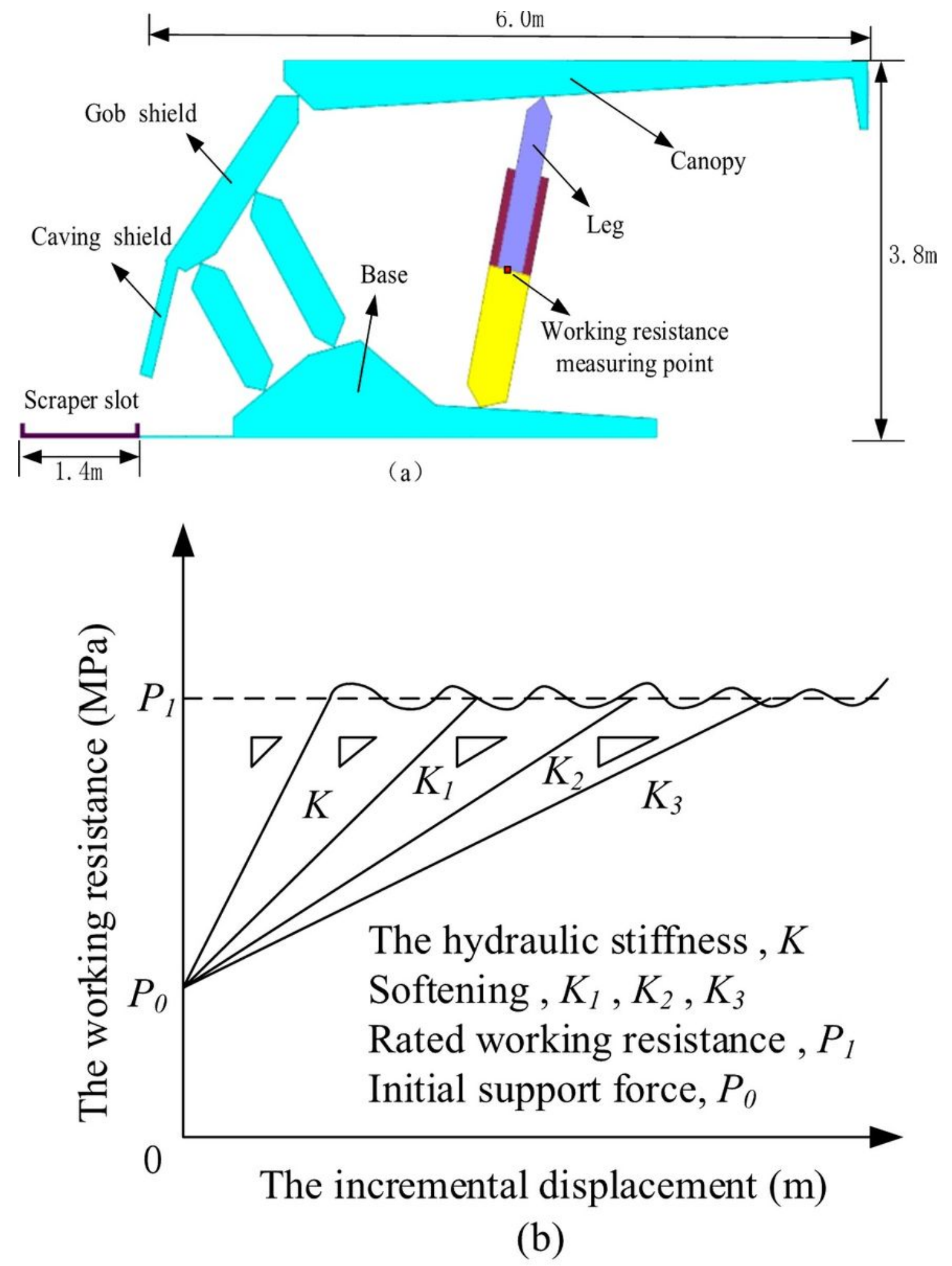

Figure 2

(a) Numerical model and arrangement of measuring points and (b) numerical constitutive curve of support 


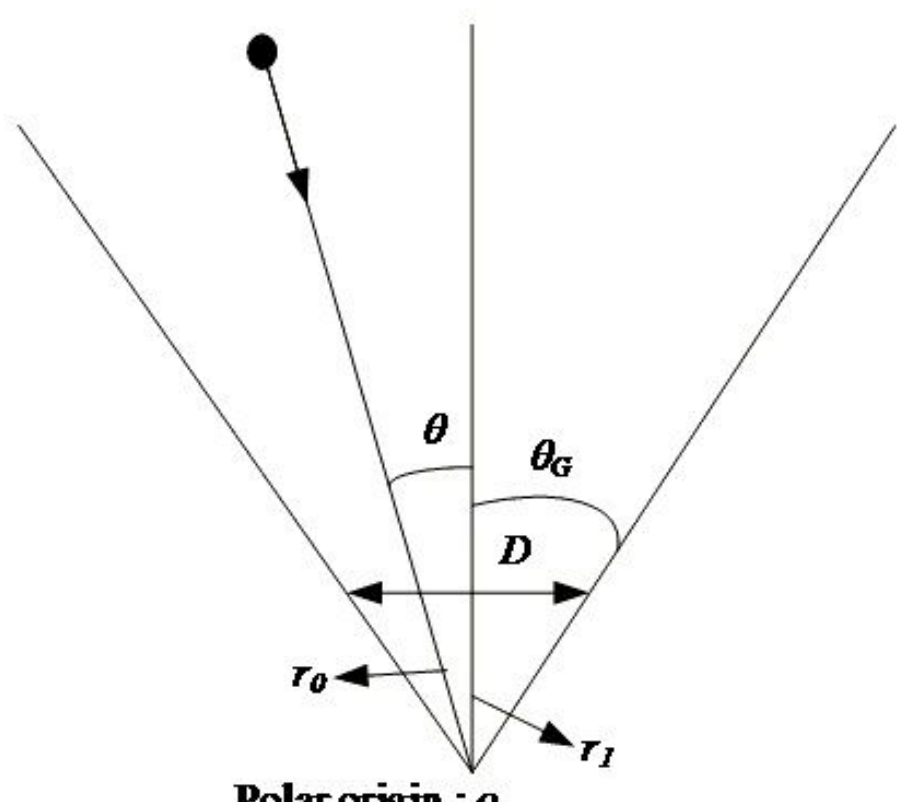

Polar origin : $o$

(a) Architecture of the Bergmark-Roos model

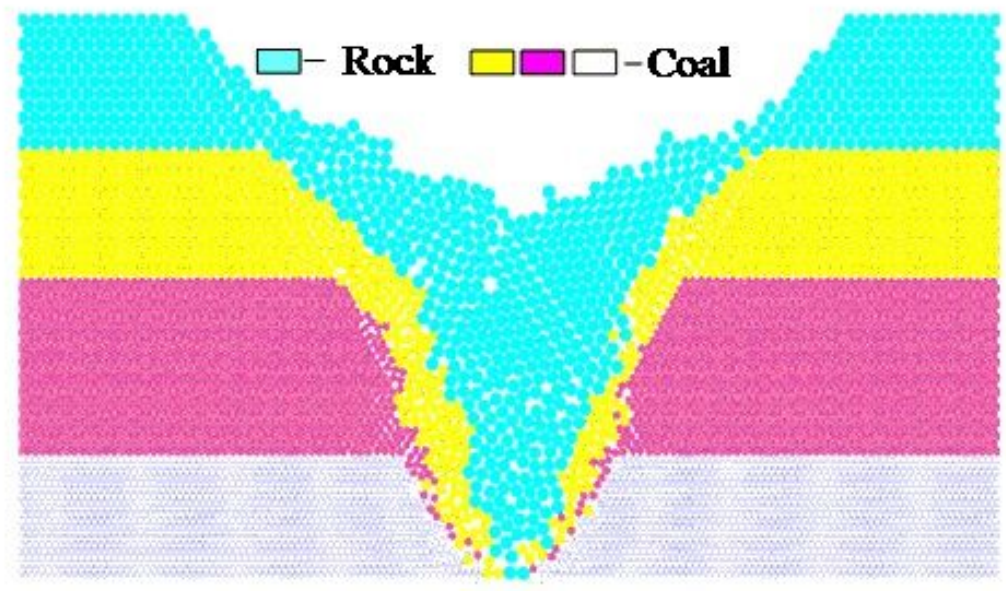

(c) The coal-rock interface after coal drawing

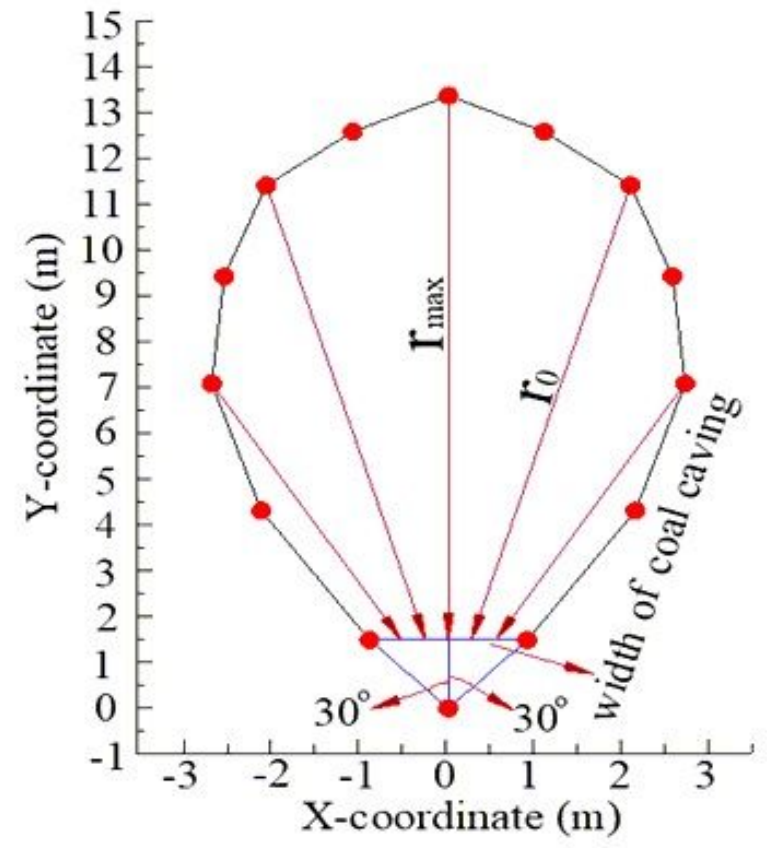

(b) theory model

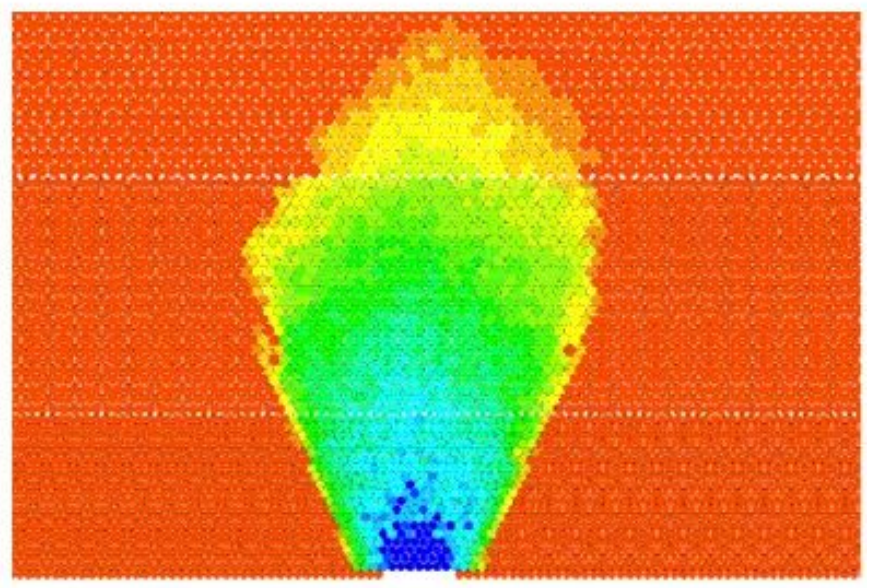

(d) Top coal caving body diagram

Figure 3

Comparison between the theoretical model and the numerical results of the top-coal drawing body 


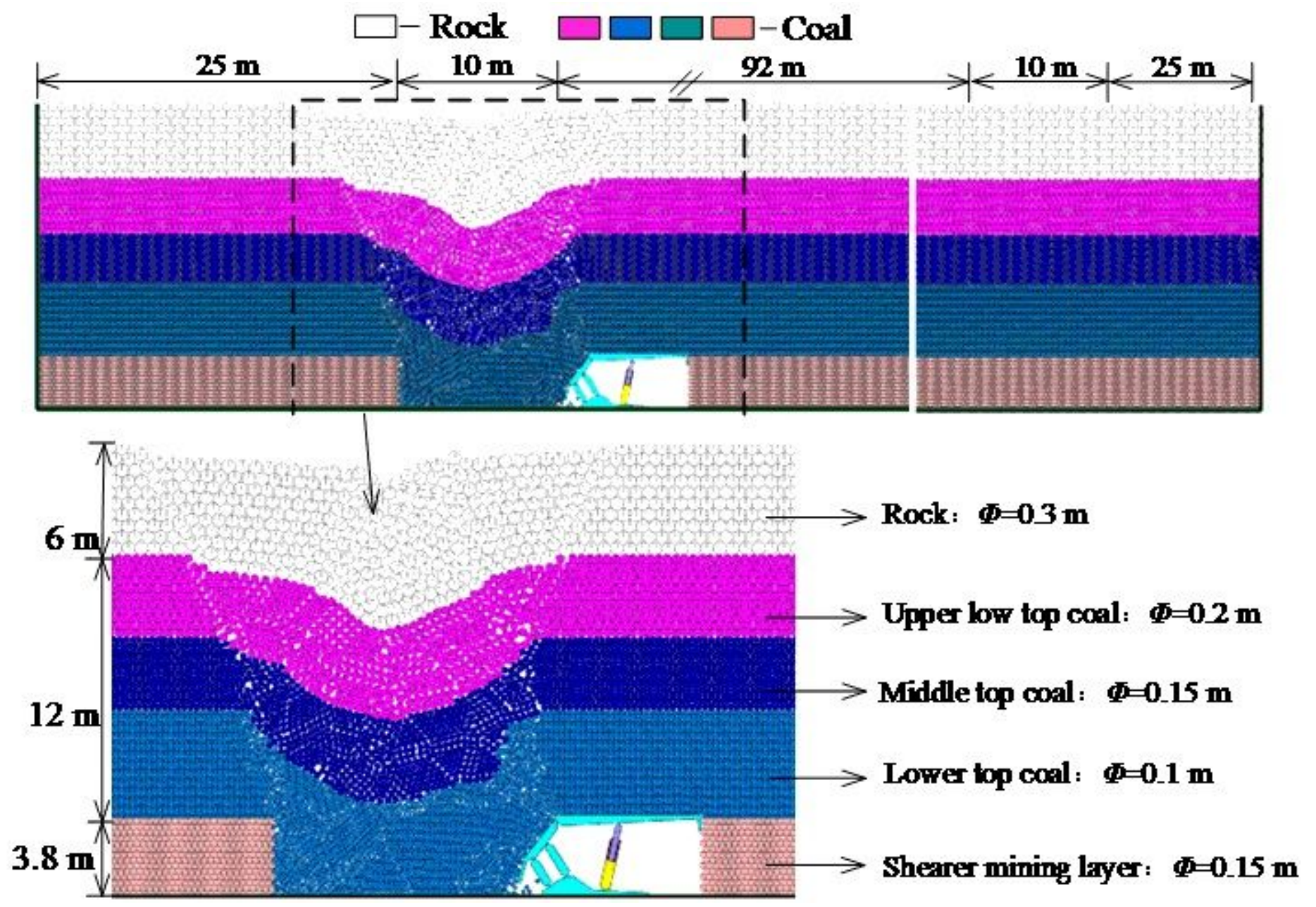

Figure 4

Numerical model 


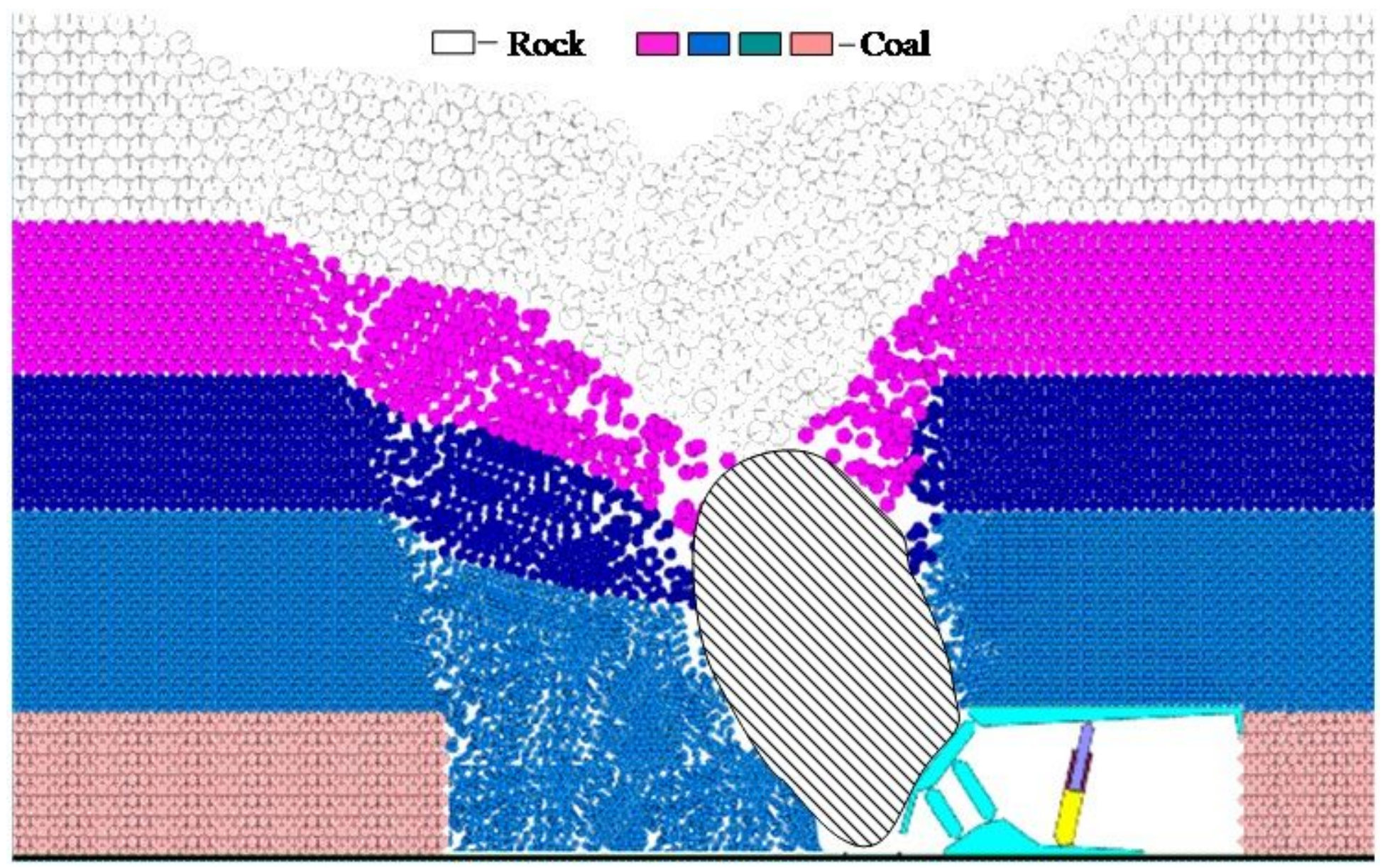

Figure 5

The top-coal caving body shape 


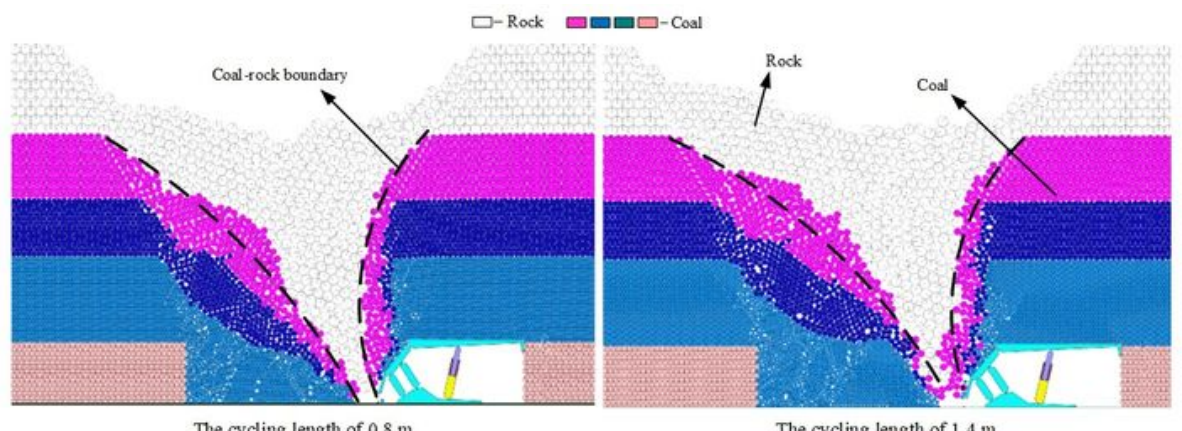

(a) The furst coal caving

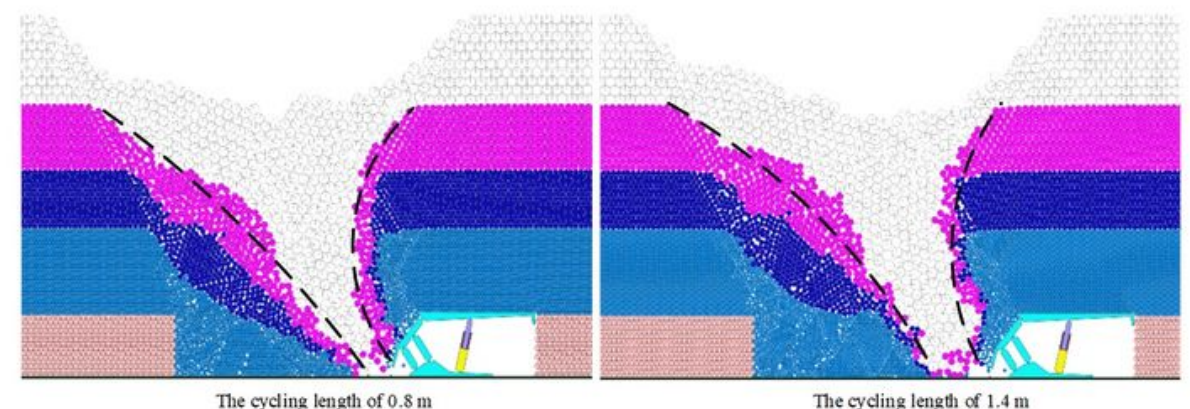

(b) The third coal caving

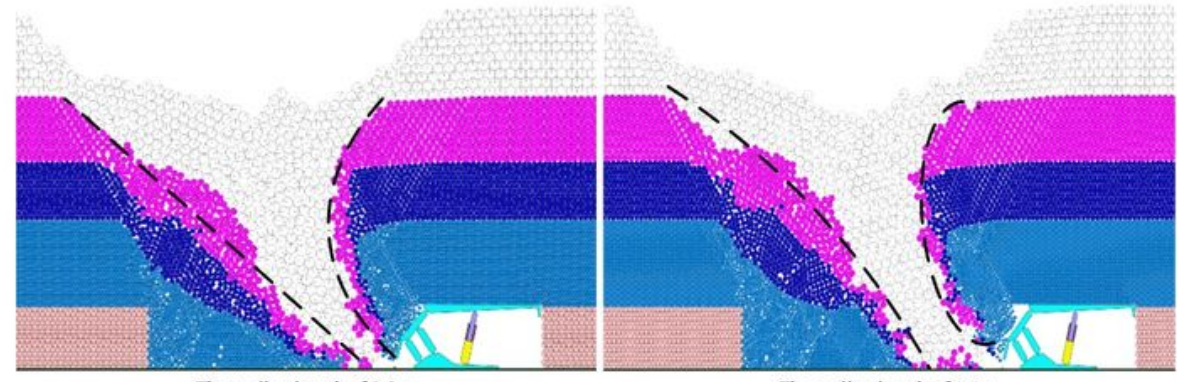

(c) The fifth coal caving

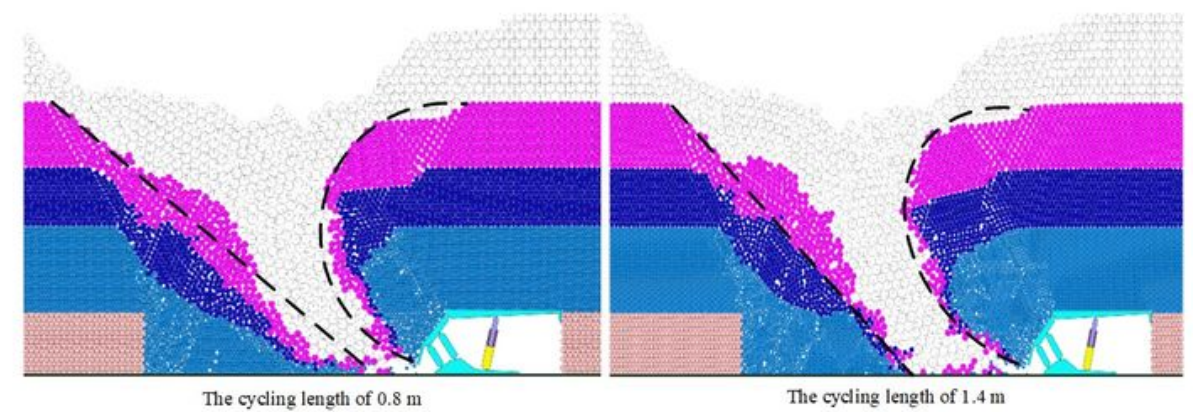

(d) The 7th coal caving

\section{Figure 6}

Evolution of the rock-coal interface during the first 7 top-coal drawing cycles The mechanism of the lost coal in the gob with a strip distribution 


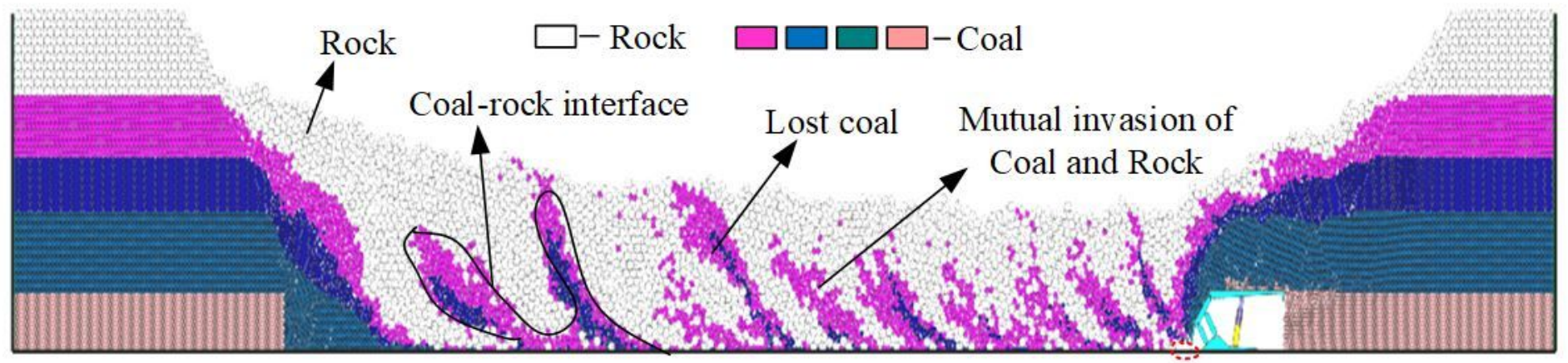

Figure 7

Drawn top-coal caving situation under the cycle step length of $0.8 \mathrm{~m}$ 

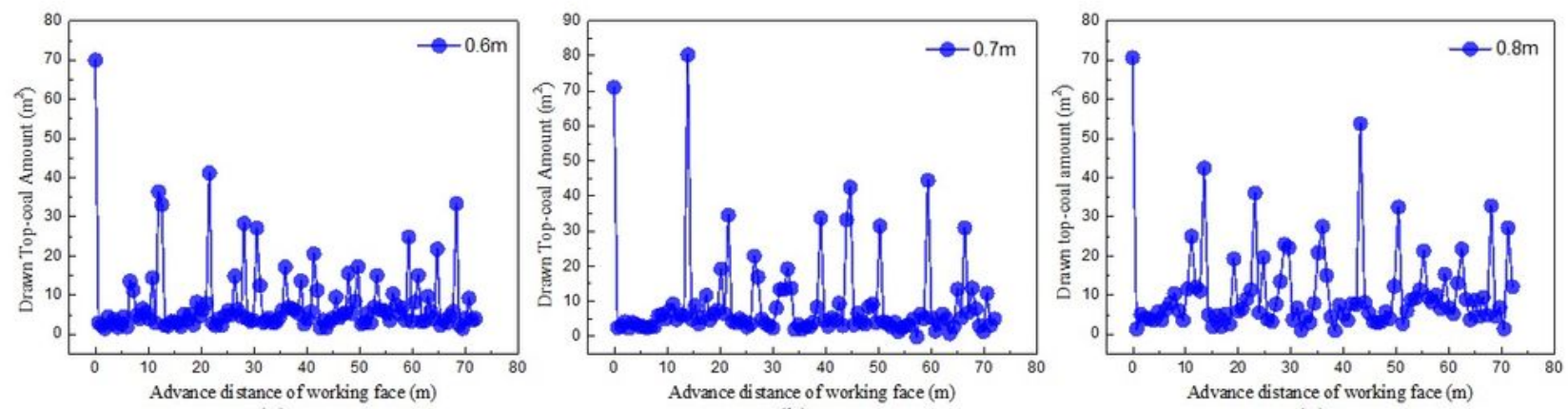

(a)

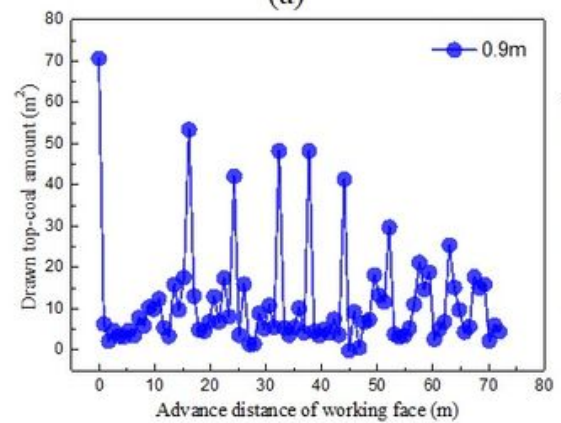

(d)

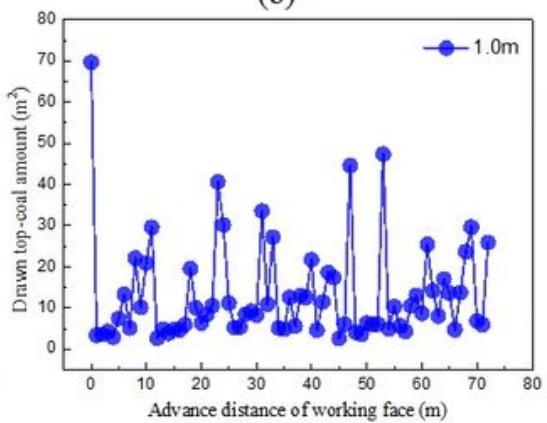

(e)

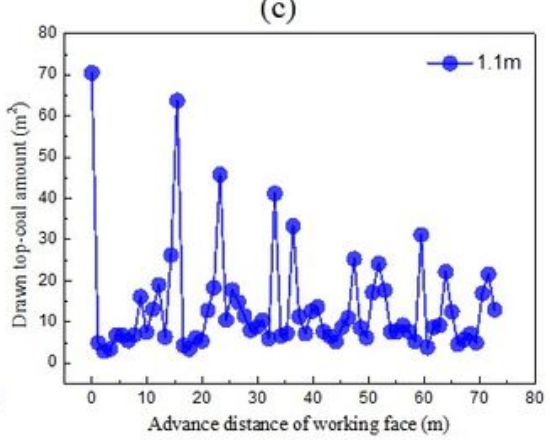

(f)
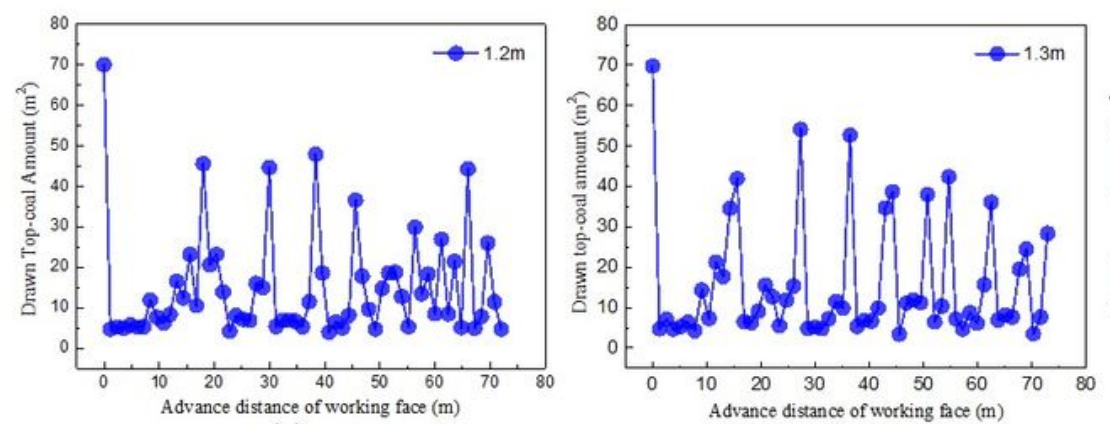

(h)

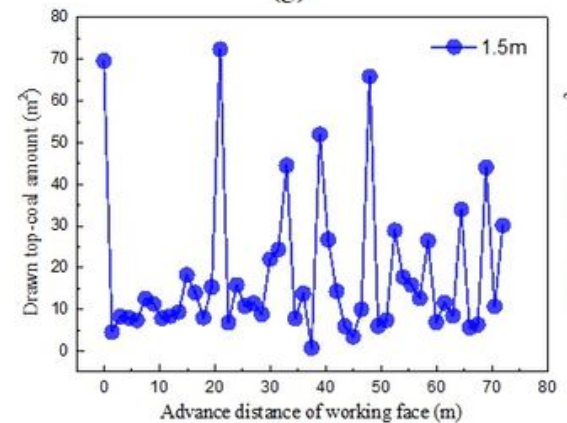

(j)
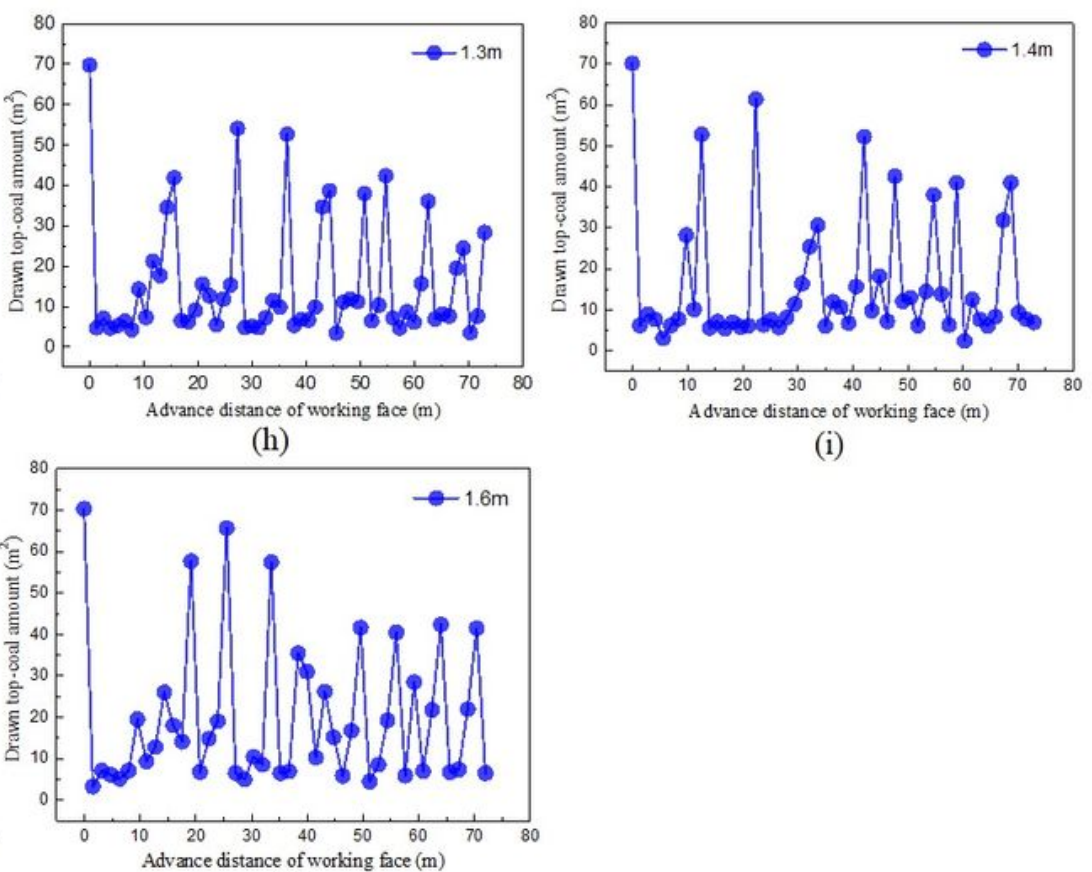

(i)

\section{Figure 8}

The amount of top-coal drawing at a single CSL under different drawing CSLS 


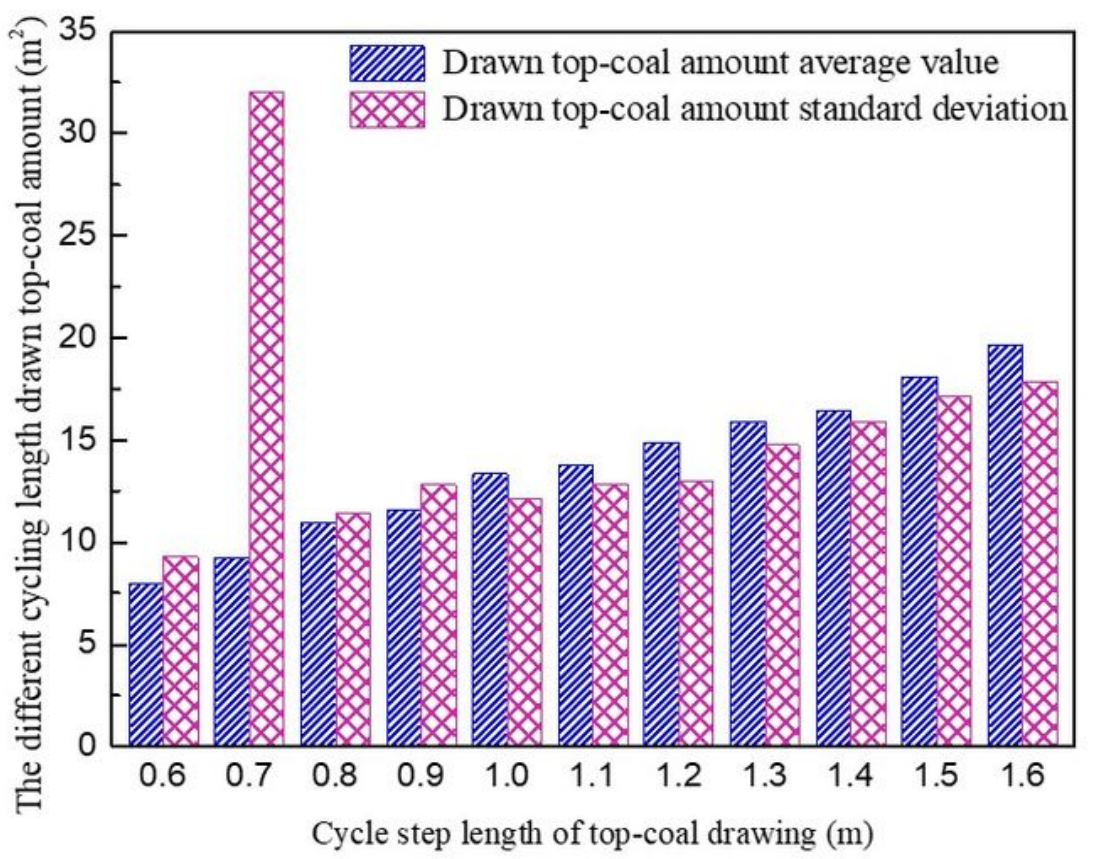

(a)

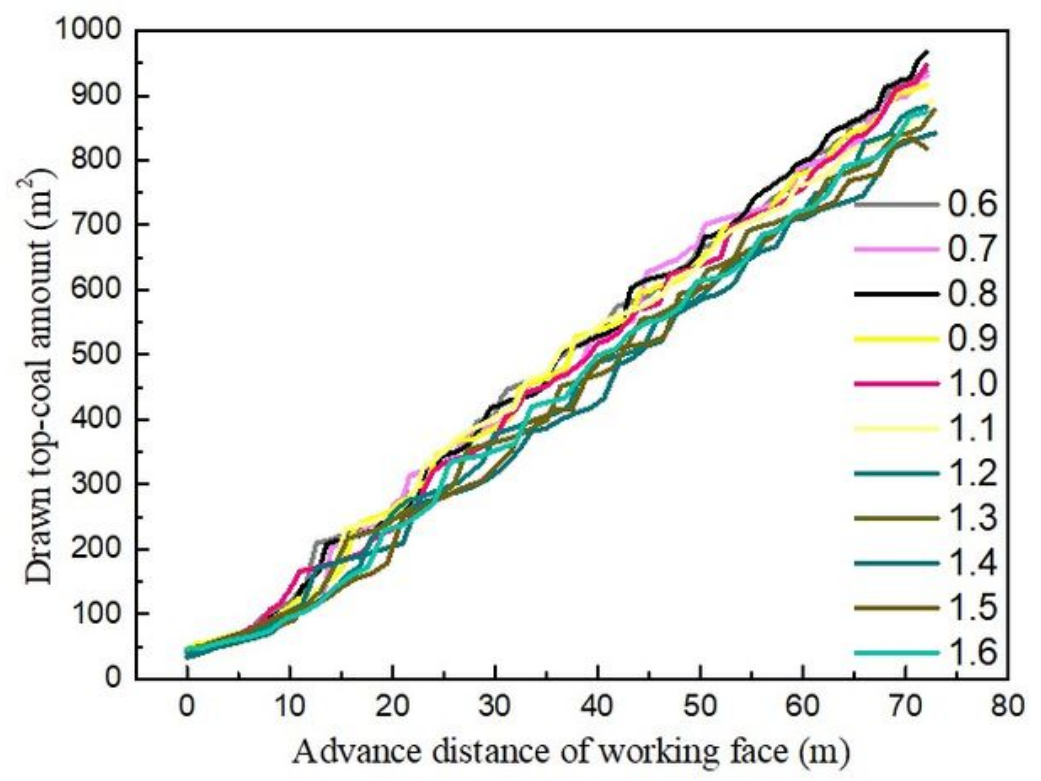

(b)

\section{Figure 9}

(a) Comparison of the average value and standard deviation of top-coal discharge within a single moving step of different coal drawing CSLs, and (b) Variation diagram of top-coal discharge with increasing advancing distance 


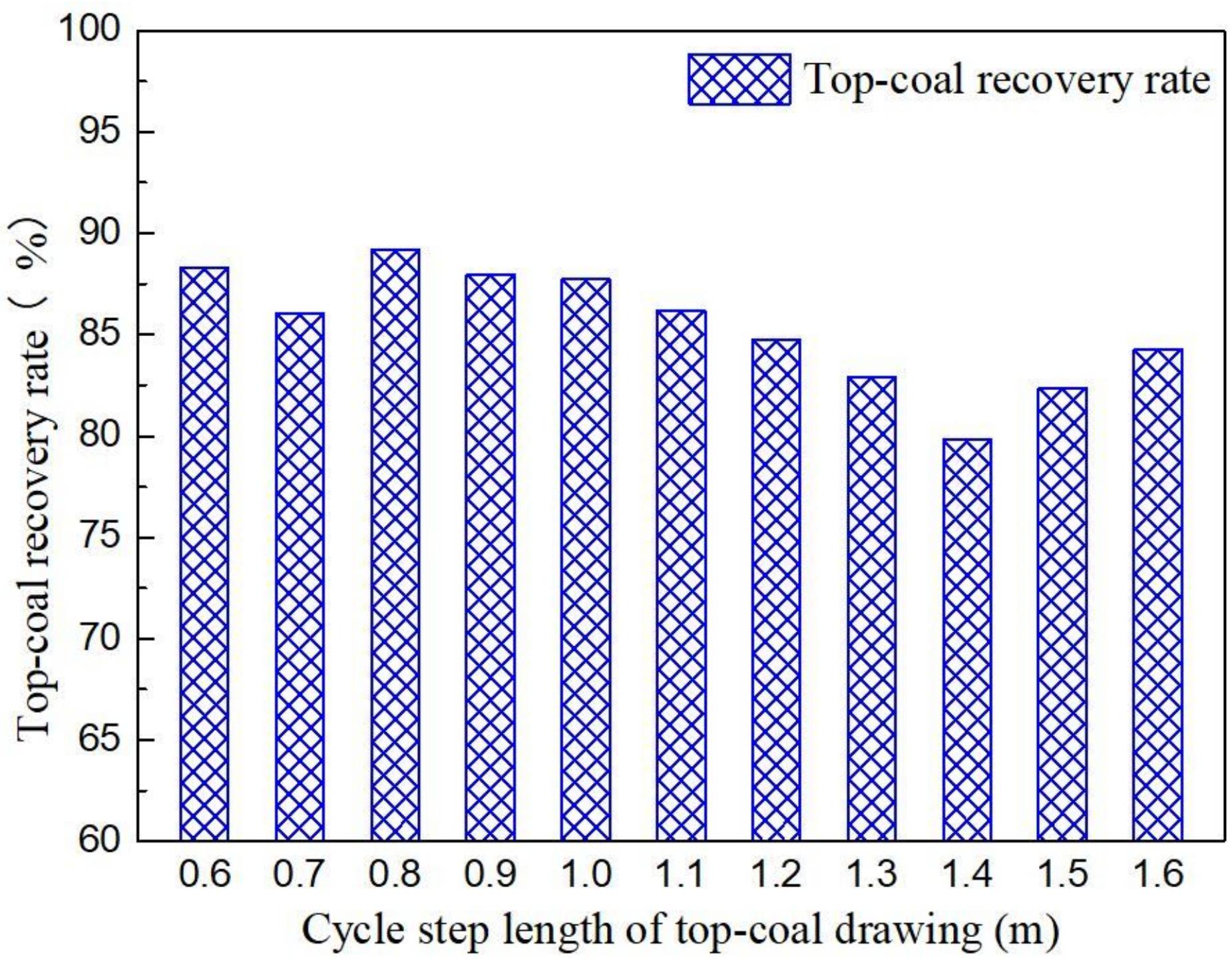

Figure 10

Change in the top-coal recovery rate under different cycle step lengths 